\title{
A novel non-genetic murine model of hyperglycemia and hyperlipidemia-associated
} accelerated atherosclerosis

Susanne Gaul ${ }^{1 *}, \mathrm{PhD}$; Khurrum Shahzad ${ }^{2 *}, \mathrm{PhD}$; Rebekka Medert ${ }^{3,5 *}, \mathrm{PhD}$; Ihsan $\mathrm{Gadi}^{2}$, Christina Mäder ${ }^{1}$, Dagmar Schumacher, PhD ${ }^{3,5}$; Angela Wirth ${ }^{3}$, PhD; Saira Ambreen², Sameen Fatima $^{2}$, Jes-Niels Boeckel ${ }^{1}, \mathrm{PhD}$, Hamzah Khawaja ${ }^{2}$, Jan Haas ${ }^{4,5}, \mathrm{PhD}$; Maik Brune ${ }^{6}, \mathrm{MD}$; Peter P Nawroth ${ }^{6}$, Prof., MD; Berend Isermann²\#, Prof., MD; Ulrich Laufs ${ }^{1 \#, ~ P r o f ., ~ M D ; ~ M a r c ~}$

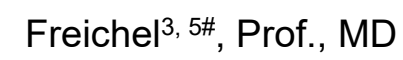

${ }^{1}$ Klinik und Poliklinik für Kardiologie, Universitätsklinikum Leipzig, Leipzig, Germany

2 Laboratory Medicine, Clinical Chemistry and Molecular Diagnostic, University Hospital Leipzig, Leipzig, Germany

${ }^{3}$ Institute of Pharmacology, Heidelberg University, Heidelberg, Germany

${ }^{4}$ Department of Internal Medicine III, Heidelberg University, Heidelberg, Germany

${ }^{5}$ DZHK (German Centre for Cardiovascular Research), partner site Heidelberg/Mannheim, Germany

${ }^{6}$ Internal Medicine I and Clinical Chemistry, German Diabetes Center (DZD), Heidelberg University, Heidelberg, Germany

*equally contributing first author; " equally contributing last author

\section{Corresponding authors:}

\section{Khurrum Shahzad}

Institute of Laboratory Medicine, Clinical Chemistry and Molecular Diagnostic, University Hospital, Leipzig, Liebigstr.27, Leipzig 04103, Germany,

\section{Email: khurrum.shahzad@medizin.uni-leipzig.de}

Marc Freichel

Institute of Pharmacology, Heidelberg University, Im Neuenheimer Feld 366, 69120

Heidelberg, Germany;

Email: marc.freichel@pharma.uni-heidelberg.de 


\section{Abstract}

Objective: Atherosclerosis, the main pathology underlying cardiovascular diseases is accelerated in diabetic patients. Genetic mouse models require breeding efforts which are time-consuming and costly. To establish a new non-genetic model of inducible metabolic risk factors mimicking hyperlipidemia, hyperglycemia, or both and allowing to detect phenotypic differences dependent on the metabolic stressor(s).

Methods and Results: Wild type mice were injected with gain-of-function PCSK9D377Y (proprotein convertase subtilisin/kexin type 9) mutant adeno-associated viral particles (AAV) and streptozotocin and fed either a high-fat diet (HFD) or high-cholesterol/high fat-diet (Paigen diet, PD). Combined hyperlipidemic and hyperglycemic (HGHCi) mice, but not hyperlipidemia $(\mathrm{HCi})$ alone, display characteristic features of accelerated atherosclerosis. Atherosclerotic plaques of $\mathrm{HGHCi}$ animals were larger, showed a less stable phenotype, contained more macrophages and less smooth muscle cells. These findings were observed both at early (12 weeks) and late (20 weeks) time points on both HFD or PD diet. Differences between the $\mathrm{HGHCi}$ and $\mathrm{HCi}$ model were confirmed using RNAseq analysis revealing that significantly more genes are dysregulated in mice with combined hyperlipidemia and hyperglycemia as compared to the hyperlipidemia only group. The $\mathrm{HGHCi}$-associated genes were related to pathways regulating inflammation, cellular metabolism and collagen degradation. PD accelerates atherosclerosis in mice and shows plaque formation already after 8 weeks, therefore, representing a fast direct inducible hyperglycemic atherosclerosis model.

Conclusion: We established a non-genetic inducible mouse model allowing comparative analyses of atherosclerosis in $\mathrm{HCi}$ and $\mathrm{HGHCi}$ conditions and its modification by diet, allowing analyses of multiple metabolic hits in mice.

Keywords: animal model of disease, atherosclerosis, diabetes, hyperglycemia, hyperlipidemia, PCSK9, Streptozotocin 


\section{Nonstandard Abbreviations and Acronyms}

63 ApoE

apolipoprotein E

64 BSA

bovine serum albumin

65 BCA

bicinchoninic acid

66 DM

diabetes mellitus

67 DAPI

4',6-Diamidino-2-Phenylindole, Dihydrochloride

68 HFD

high fat diet

69 HRP

horseradish peroxidase

70 LDLR

low-density lipoprotein receptor

71 NOD

non-obese diabetic

72 OCT

optimal cutting temperature

73 PD

paigen diet

74 PCSK9

proprotein convertase subtilisin/kexin type 9

75 PBS

phosphate buffer saline

76 RIPA

radioimmunoprecipitation assay

77 RNAseq

RNA sequencing

78 rAAV

recombinant adeno-associated virus

79 STZ

streptozotocin

80

a-SMA a smooth muscle actin 


\section{Introduction}

Atherosclerotic cardiovascular diseases including coronary artery disease (CAD) and its complications are a leading cause of mortality and morbidity globally [1]. The risk of CAD is markedly increased in patients with both type 1 and type 2 diabetes mellitus (DM), with CAD events occurring earlier in patients with diabetes mellitus[2]. About $10 \%$ of total vascular deaths have been attributed to diabetes mellitus and its complications[2]. Despite recent studies showing cardioprotective effects of new antidiabetic agents[3], there is high need to understand how diabetes associated alterations, particularly chronic hyperglycemia and metabolic alterations evoked thereby, aggravates atherosclerosis in CAD patients as basis for the development of more effective treatments for these high risk patients.

Currently used mouse models of hyperglycemia-associated atherosclerosis require a combination of streptozotocin (STZ) and crossbreeding with either Apolipoprotein $\mathrm{E}\left(\mathrm{ApoE}^{-{ }^{-}}\right)$ or low density lipoprotein receptor $\left(\mathrm{LDLR}^{-/-}\right)$genetic knock-out mice, or alternatively, a double crossbreeding of $\mathrm{ApoE}^{-/-}$or LDLR ${ }^{-/-}$with insulin receptor (Ins2 ${ }^{+}$, Akita) mutant mice[4]. Some murine models such as STZ-injected human apoB-expressing transgenic mice[5] or the nonobese diabetic (NOD) mice[6] are resistant to the development of atherosclerosis. In addition, crossing of mouse lines is time-consuming and costly. In particular, if mouse models harbouring other genetic manipulations are to be used, backcrossing becomes a major issue. Thus, there is a high demand to generate an inducible mouse model of multiple metabolic hits, e.g. hyperlipidemia and hyperglycemia, which can be used alone or in combination with other genetic modifications. Bjorklund et al. developed a non-genetic mouse model of atherosclerosis induced by a single injection of recombinant adeno-associated virus (rAAV) encoding a hyperactive proprotein convertase subtilisin/kexin type 9 (PCSK9) ${ }^{\mathrm{D} 37 \mathrm{Y}}$ mutant followed by high-fat diet feeding that has been used in non-diabetic settings $[7,8]$ as well as in mature diabetic Akita mice where they showed diabetic- associated accelerated atherosclerosis[7]. Here, we combined injections of rAAV8-PCSK9D377Y and STZ followed by high-fat diet (HFD) feeding to generate a rapid and versatile method to induce a hyperglycemia- accelerated mouse model of atherosclerosis.

\section{Materials and Methods}

All informations regarding material and reagents are listed in the major resources table.

\section{Reagents}

The following antibodies were used in the current study: rabbit anti-LDLR (R\&D Systems, United States), mouse anti- $\beta$ actin (Abcepta Inc. United States), goat anti-rabbit IgG HRP (Cell Signaling Technology, Germany), rat anti-MOMA-2, rabbit anti-CD68 and rabbit anti- alpha smooth muscle actin ( $\alpha-S M A)$ (abcam, Germany), rabbit anti-GAPDH (Sigma-Aldrich, 
Germany). The following secondary antibodies for immunofluorescence were used: Texas red rabbit anti-mouse IgG (Vector Laboratories, United States), Goat anti-Rat IgG ( $\mathrm{H}+\mathrm{L})$ CrossAdsorbed Secondary Antibody, Alexa Fluor 568 (ThermoFisher, United States). Other reagents were as follows: BCA reagent (Perbio Science, Germany); vectashield mounting medium with DAPI (Vector Laboratories, United States); nitrocellulose membrane (Bio-Rad, USA) and immobilon ${ }^{\mathrm{TM}}$ western chemiluminescent HRP substrate (Merck, Millipore, United States); streptozotocin (Enzo Life Sciences, Germany); Oil-Red O (Sigma-Aldrich, Germany); accu-chek test strips, accu-check glucometer, protease inhibitor cocktail (Roche Diagnostics, Germany); albumin fraction V, hematoxylin Gill II, acrylamide, agarose (Carl ROTH, Germany); aqueous mounting medium (ZYTOMED, Germany); "high fat diet" (HFD) experimental food (Western-type diet containing $21 \%$ fat and $0.21 \%$ cholesterol or paigen diet containing $16 \%$ fat, $1.25 \%$ cholesterol, and $0.5 \%$ sodium cholate, Ssniff, Germany); PBS (Life Technologies, Germany); rompun 2 \% (Bayer, Germany); ketamine $10 \%$ (beta-pharm, Germany).

Mice

Eight weeks old male LDLR ${ }^{-/-}$(002207) mice were obtained from the Jackson Laboratory (Bar Harbor, ME, USA). Male wild-type C57BL/6N were obtained from Charles River Laboratories (Wilmington, MA, USA). Only age-matched male mice were used throughout the study (6-7 mice per group). All animal experiments comply with the ARRIVE guidelines and are carried out in accordance with the Directive 2010/63/EU guidelines. They were conducted following standards and procedures approved by the local Animal Care and Use Committee (359185.81/G-185/19, Regierungspräsidium Karlsruhe, Germany).

\section{Generation and quantification of rAAV8 viral particles}

Recombinant rAAV8 vector particles were generated and purified using the iodixanol gradient ultracentrifugation method[9, 10]. The rAAV8 production was carried out using HEK293T cells. First, $1.8 \times 10^{8}$ HEK293T cells were seeded in a ten chamber CellStack (Corning, USA) and cultured in DMEM+ Glutamax (Gibco, Thermo Fisher Scientific, USA) supplemented with 10\% fetal bovine serum (FBS) and 1\% penicillin G / streptomycin. After 48 hours, a 1:1:1 molar ratio of pAAV-D377YmPCSK9-bGHpA plasmid[7], the rep-cap AAV8 helper plasmid and an adenoviral helper plasmid was mixed and transfected using polyethylenimine (PEI) (Polyscience, USA). The cells were harvested in $3 \mathrm{ml}$ lysis buffer and lysed by four freezethaw cycles 72 hours after transfection. The vector particles were purified using an iodixanol (Progen, Germany) gradient consisting of four phases with decreasing density $(60 \%, 40 \%$, $25 \%, 15 \%)$ and ultracentrifugation at $50,000 \times \mathrm{g}$ for $135 \mathrm{~min}$ at $4^{\circ} \mathrm{C}$. Approximately $3 \mathrm{ml}$ of the $40 \%$ phase, in which predominantly full virus particles accumulate, were recovered with a $27 \mathrm{G}$ needle. Finally, the vector solution was buffered into PBS using dialysis tubes (Zeba Spin 
Desalting Columns 7K MWCO, Thermo Scientific, USA) and concentrated (VivaSpin 10K MWCO, Sartorius, Germany). Vector titer was quantified as genome copy numbers per $\mathrm{ml}$ using a qPCR SYBR-Green assay (Biorad) and primers sequences which are specific for the

Induction of atherosclerosis by hypercholesterolemia $(\mathrm{HCi})$ and hypercholesterolemia and hyperglycemia (HGHCi) in mice

Adeno-associated viral vectors encoding the gain-of-function variant D377Y of the murine PCSK9 (rAAV8-PCSK9 ${ }^{\mathrm{D} 37 \mathrm{Y}}$ ) under the control of liver-specific promoter were delivered via a single retro-orbital sinus injection $\left(1.0 \times 10^{11}\right.$ viral genomes/mouse), and treated animals were either fed high-fat Western-type diet (HFD, containing $21 \%$ fat and $0.21 \%$ cholesterol), a highcholesterol/high-fat Paigen diet (PD, containing $16 \%$ fat, $1.25 \%$ cholesterol, and $0.5 \%$ sodium cholate) to induce chronic hypercholesterolemia ( $\mathrm{HCi})$. Control animals not treated with rAAV8-PCSK9D377Y were fed a high-fat diet (graphic abstract).

To induce chronic hyperglycemia and hypercholesterolemia $(\mathrm{HGHCi})$, mice were injected with streptozotocin (STZ, $60 \mathrm{mg} / \mathrm{kg}$, intraperitoneally, once daily for five consecutive days, freshly dissolved in $0.05 \mathrm{M}$ sterile sodium citrate, $\mathrm{pH}$ 4.5) one week after rAAV8-PCSK9D377Y application. As control for STZ injections mice received injections with equal volume of $0.05 \mathrm{M}$ sodium citrate, $\mathrm{pH} 4.5$ for 5 days. As PCSK9 expression leads to degradation of low density lipoprotein (LDL) receptors, we quantitatively compared the development of atherosclerotic plaque formation in the inducible $\mathrm{HCi}$ and $\mathrm{HGHCi}$ models with $\mathrm{LDLR}^{-/-}$mice fed HFD or PD. LDLR $^{-1-}$ mice served as the established control model for hypercholesterolemia evoked atherosclerosis[12]. Blood glucose levels were monitored twice a week using Accu-Chek Aviva system (Roche, USA) and maintained in a range of 300-500 mg/dl. Body weight was measured once weekly. HFD and/or hyperglycemia (minimum $300 \mathrm{mg} / \mathrm{dl}$ ) was maintained for up to 12 or 20 weeks. In the first 4 weeks of the study some mice in the PD as well as in the HFD groups did not tolerate the food. These animals showed a strong reduction in body weight, which is defined as a termination criterion. Consequently, these mice were removed from the study. Mice fed the PD were analysed already after 8-9 weeks due to early mortality in the hyperglycemic group (Supplementary Figure I). At respective study endpoints, mice were sacrificed and atherosclerotic plaque morphology was analysed as previously described[13$15]$.

Total plaque size (\%) is defined as the size of the plaque comprising all parts of the atherosclerosis (fibrous cap, necrotic tissue, fibrous tissue etc.) within the vessel lumen. Necrotic core (in \%) is defined as the area stained blue upon MOVATs pentachrome staining and is presented as the percentage of the total plaque size. Fibrous cap thickness (in $\mu \mathrm{m}$ ) is 
the minimal thickness of the fibrous tissue overlaying a necrotic core. If multiple necrotic cores are present within one plaque, the thickness of all fibrous caps is determined and the average was used for further analyses. Thickness was measured using ImageJ sofware using freehand tool $[13,14]$.

\section{Analysis of mice}

At the end of study period (12 or 20 weeks for HFD or 8 weeks for PD) body weight was measured and mice were sacrificed[14-16]. Blood samples were obtained from the inferior vena cava of anticoagulated mice (500 U unfractionated heparin, intraperitoneally). Blood was centrifuged at 2,000 $\mathrm{xg}$ for $20 \mathrm{~min}$ at $4^{\circ} \mathrm{C}$ and plasma was snap frozen in liquid nitrogen. Mice were perfused with ice-cold PBS for $10 \mathrm{~min}$ and the heart, aortic arches, including brachiocephalic arteries, were embedded in O.C.T. compound and snap frozen. Brachiocephalic arteries (from distal to proximal) and upper hearts (aortic roots) were sectioned at 5 and $10 \mu \mathrm{m}$ thickness, respectively.

\section{Analysis of plasma lipids}

Heparin plasma was prepared for the measurement of plasma lipids. A total of $500-700 \mu \mathrm{l}$ blood per mouse was collected in heparin tubes and centrifuged at $3,500 \times \mathrm{g}$ for $10 \mathrm{~min}$ at room temperature. Plasma was transferred in a $1.5 \mathrm{ml}$ tube and stored at $-80^{\circ} \mathrm{C}$. Plasma samples of HFD and PD fed mice were diluted $1: 5$ with $0.9 \% \mathrm{NaCl}$ before cholesterol and triglycerides measurements. Plasma samples were analyzed in the accredited central laboratory of the Heidelberg University hospital using standard operating procedures according to the manufacturers' instructions. Cholesterol and triglycerides were analyzed on a Siemens ADVIA Chemistry XPT System (reagents kits 04993681 and 10697575, respectively).

\section{Histology}

Oil- Red O staining was conducted on frozen sections of the aortic roots or brachiocephalic arteries[14, 17]. Cryopreserved sections of the brachiocephalic arteries and aortic roots (5 and $10 \mu \mathrm{m}$ respectively) were fixed in ice cold acetone for $2 \mathrm{~min}$, rinsed twice in ice cold $1 \times$ PBS, and were stained with Oil- Red O for $10 \mathrm{~min}$. Sections were rinsed twice with distilled water for 20 seconds and once in running tap water for $10 \mathrm{~min}$. Sections were then counterstained with haematoxylin for 40 seconds, rinsed in tap water, and mounted with aqueous mounting medium. MOVAT's stain was performed on frozen sections of brachiocephalic arteries. Frozen sections $(5 \mu \mathrm{m})$ were fixed in Bouin's solution at $50^{\circ} \mathrm{C}$ for $10 \mathrm{~min}$ and stained with $5 \%$ sodium thiosulfate for $5 \mathrm{~min}, 1 \%$ alcian blue for $15 \mathrm{~min}$, alkaline alcohol for $10 \mathrm{~min}$, Movat's Weigert's solution for $20 \mathrm{~min}$, crocein scarlet acid / fuchsin solution for $1 \mathrm{~min}, 5 \%$ phosphotungstic acid 
washed with tap water and distilled water. Sections were then covered with cytoseal mounting medium. Every $15^{\text {th }}$ section $(\sim 90 \mu \mathrm{m})$ of the brachiocephalic arteries and aortic roots were analysed to quantify the plaque area. For histological analysis images were captured with a Keyence BZ-X810 fluorescence microscope (aortic root) and an Olympus Bx43-Microscope (brachiocephalic arteries). The Image Pro Plus software (version 6.0) software was used for image analysis[14, 15, 17].

Cryosections were used for picrosirius red staining (Sigma-Aldrich, Germany) according to the manufacturer's instructions. Tissue section were then stained with picrosirius red solution for $1 \mathrm{~h}$ at room temperature. Sections were then washed 2 times- in acidified water $(5 \mathrm{ml}$ glacial acetic acid to 1 liter of water) and mounted. For histological analysis, images were captured on a Keyence BZ-X810 fluorescence microscope and ImageJ software was used.

\section{Immunohistochemistry and immunofluorescence staining}

For immunohistochemistry and immunofluorescence staining, frozen sections of brachiocephalic arteries or aortic roots were fixed in ice cold acetone for $8 \mathrm{~min}$, washed twice with ice cold PBS and incubated in 2\% BSA in PBST for $1 \mathrm{hr}$. Sections were then incubated for overnight at $4^{\circ} \mathrm{C}$ with primary antibodies against $\alpha$-SMA (smooth muscle cells marker) and CD68 (macrophages markers). Sections incubated without primary antibodies were used as negative controls for background correction. After overnight incubation the sections were washed three times with PBS followed by incubation with corresponding horseradish peroxidase (HRP)labelled secondary antibodies. After washing, tissues were counterstained using 3,3'diaminobenzidine (DAB)/haematoxylin. Images were visualized, captured, and analysed using a Keyence BZ-X810 all-in-one fluorescence microscope and an Olympus Bx43-Microscope (Olympus, Hamburg, Germany). The Image J software (Version 1.8.0.) was used for image analysis. Primary antibody against MOMA-2 (1:50, macrophages marker) was incubated for overnight at $4^{\circ} \mathrm{C}$ followed by washing three times with PBS and incubation with fluorescently labelled corresponding secondary antibody. Sections incubated without secondary antibody were used as negative controls and for background correction. After washing, nuclear counterstaining was conducted using mounting medium with DAPI. Images were visualized, captured, and analysed using a fluorescence microscope (Keyence BZ-X810 and Olympus Bx43-Microscope) using the same settings in experimental and control groups. Analyses were performed by two independent blinded investigators. Image $\mathrm{J}$ software was used for image analysis.

\section{Immunoblotting}

Proteins were isolated and immunoblotting was performed as described[18]. Mouse livers were weighted and adjusted volume of RIPA buffer containing protease inhibitor cocktail $(100 \mu \mathrm{l} / 10$ 
$\mathrm{mg}$ ) was added. Tissue was homogenized mechanically using $20 \mathrm{G}$ and $25 \mathrm{G}$ needles followed by a 30 min incubation on ice with sequential vortexing. Samples were centrifuged at $12,000 \mathrm{x}$ $\mathrm{g}$ for $20 \mathrm{~min}$ at $4^{\circ} \mathrm{C}$. Supernatant was transferred to a fresh tube and protein concentration was determined using the Pierce ${ }^{\mathrm{TM}}$ BCA Protein Assay Kit following manufacturer's instructions and Varioskan Lux plate reader (Thermo Fisher Scientific, Waltham, MA, USA). Samples were separated using the Mini-PROTEAN $®$ TGX ${ }^{\text {TM }}$ Precast Gel 4-15\% (Bio-Rad Laboratories, Inc., Hercules CA, USA) and transferred to a Nitrocellulose membrane. Membranes were incubated with Invitrogen No-Stain solution for 10 min and blocked for $1 \mathrm{~h}$ in $5 \%$ low-fat milk dissolved in TBS-T. Incubation with primary anti-mLDLR antibody and anti- $\beta$-actin was performed overnight at $4^{\circ} \mathrm{C}$. Membranes were incubated with the corresponding secondary rabbit anti-goat Immunoglobulins/HRP and Goat Anti-Mouse Immunoglobulins/HRP for $1 \mathrm{~h}$ at room temperature. Millipore Immobilon Classico Western HRP Substrate was applied to detect the signal using iBright 1500 (Thermo Fisher Scientific, Waltham, MA, USA). Densiometric analysis was performed using ImageJ software.

\section{RNA-seq, functional annotation and pathway analysis}

RNA was extracted from aortic tissues (comprising the plaque and surrounding tissue) using an RNeasy mini kit (QIAGEN, Germany), and RNA concentration was measured using a nanodrop (2000C, Peq lab, Germany). The quality and integrity of RNA were controlled with an Agilent Technologies 2100 Bioanalyzer (Agilent Technologies, Waldbronn, Germany). Expression profiling was performed using RNA sequencing (RNA-seq). RNA sequencing library was generated from $500 \mathrm{ng}$ total RNA using Dynabeads $®$ mRNA DIRECT(tm) Micro Purification Kit (Thermo Fisher) for mRNA purification followed by NEBNext ${ }^{\circledR}$ Ultra(tm) II Directional RNA Library Prep Kit (New England BioLabs) according to manufacturer's protocols. The libraries were sequenced on Illumina NovaSeq 6000 using NovaSeq 6000 S2 Reagent Kit (100 cycles, paired end run) with an average of $3 \times 10^{7}$ reads per RNA sample. A quality report is generated by the FASTQC (version 0.11.8) tool for each FASTQ file. Before alignment to the reference genome, each sequence in the raw FASTQ files was trimmed on base call quality and sequencing adapter contamination using the Trim Galore! wrapper tool (version 0.4.4). Reads shorter than $20 \mathrm{bp}$ were removed from the FASTQ file. Trimmed reads were aligned to the reference genome using the open source short read aligner STAR (version 2.5.2b, https://code.google.com/p/rna-star/) with settings according to the log file. Feature counts were determined using the R package Rsubread (version 1.32.4). Only genes showing counts greater than 5 at least two times across all samples were considered for further analysis (data cleansing). Gene annotation was performed using the R package bioMaRt (version 2.38.0). Before starting the statistical analysis steps, expression data were log2 transformed and normalized according to the $50^{\text {th }}$ percentile (quartile normalization using edgeR, version 
3.24.3). Differential gene expression was calculated by the $R$ package edgeR. Statistically significant DEGs $(p<0.05$ and FDR $<0.05)$ were sorted and categorized after correcting for multiple hypothesis testing by Benjamini-Hochberg method. The threshold to identify differentially expressed genes (DEGs) was set to a logFc value of \pm 0.58 (IRI group), resulting in a 1.5-fold expression change. To identify genes differentially regulated by either hyperlipidemia $(\mathrm{HCi})$ or combined hyperglycemia and hyperlipidemia ( $\mathrm{HGHCi}$ ), DEGs between HFD (control) group and either group were identified based on a minimum logFc difference value of \pm 0.58 . Heatmapper (http://www. heatmapper.ca/) was used to generate heatmaps of gene expression data. Genes shown in the heatmap were sorted based on DEGs in the control group (HFD without PCSK9 injections) based on their log Fc values. For representation purpose, no clustering method was applied and z-score was used. Venny (version 2.1), an online interactive tool was used for comparison and identification of overlapping DEGs between different groups. Gene ontology was performed using online tool, Database for Annotation, Visualization and Integrated Discovery (DAVID) version 6.8 bioinformatics package and Benjamini Hochberg adjustment was applied to all enriched p-values to control for multiple testing. All RNAseq analyses were done by an independent blinded investigator.

\section{Statistical Analysis}

Statistical analyses were performed with Graph Pad Prism (version 7; Graph Pad Software Inc., La Jolla, CA, USA). The significance level was set at $p<0.05$ for all comparisons. The data are summarized as mean \pm standard error of the mean (SEM). Comparison of two groups were analyzed with unpaired Student's T-test. Statistical analyses of more than two groups were performed with analysis of variance (ANOVA), and Sidak's post hoc comparisons. The Kolmogorov-Smirnov test or D'Agostino-Pearson normality test was used to determine whether the data are consistent with Gaussian distribution.

\section{Results}

\section{Combination of hyperglycemia and hyperlipidemia exacerbates atherosclerosis in} PCSK9 ${ }^{\mathrm{D} 37 Y}$ expressing mice on a high-fat diet

To induce hypercholesterolemia ( $\mathrm{HCi}), 8$ weeks old C57BL/6N mice were administrated a single dose of rAAV8-PCSK9D377Y $\left(1.0 \times 10^{11}\right.$ adeno-associated viral particles, intravenously) one week before feeding a high fat diet (HFD, Western type diet). Saline-injected mice fed a HFD served as control for the rAAV8-PCSK9D377Y intervention. Saline-injected mice with genetic deficiency of low density lipoprotein receptor $\left(\mathrm{LDLR}^{-/-}\right)$on HFD served as control for rAAV8-PCSK9 ${ }^{\mathrm{D} 377}$ treatment (Figure 1A). The mice group in which hypercholesterolemia evoked by PCSK9-expression and $\mathrm{HFD}(\mathrm{HCi}$, single hit) was combined with induction of 
chronic hyperglycemia using STZ-injection (double hit) is hereon termed as HGHCi (high glucose high cholesterol - inducible) throughout the manuscript. For quantification of atherosclerotic plaque formation mice were euthanized 12 (early timepoint) or 20 (late timepoint) weeks after rAAV8-PCSK9D377Y injection and start of HFD feeding. As anticipated, rAAV8-PCSK9 ${ }^{\mathrm{D} 377 Y}$ administration, resulted in strong reduction of hepatic LDL receptor protein levels as compared with saline injected mice both after 12 and 20 weeks of intervention (Figure 1B, C). All mice thrived well and body weight (Supplementary Table 1), blood lipids and glucose levels differed among treatment groups (Figure 1D-F). Plasma cholesterol levels were higher in $\mathrm{HGHCi}$ group as compared to $\mathrm{HCi}$ animals both at early and late timepoint analysis (Figure 1D), however, plasma triglyceride levels were higher in the $\mathrm{HGHCi}$ vs $\mathrm{HCi}$ group only after 20 weeks (Figure 1E). Plasma triglyceride, cholesterol and glucose levels were comparable between rAAV8-PCSK9D377Y ( $\mathrm{HCi}$ group) and LDLR ${ }^{-/}$mice on HFD (Figure 1D-F).

Analyses of haematoxylin and eosin (H\&E) and Oil-Red O stained aortic root sections showed larger atherosclerotic plaques in $\mathrm{HGHCi}$ mice compared to $\mathrm{HCi}$ mice, both at early and late timepoint analysis (Figure 2A-D). Control mice had no lesions, whereas all rAAV8PCSK9D377Y-injected mice on HFD (HCi group) developed atherosclerosis to a similar extent like LDLR ${ }^{-/-}$mice on HFD (Supplementary Figure II, A-H). In addition, HGHCi mice on HFD had larger plaques than LDLR ${ }^{-/}$mice. Likewise, atherosclerotic plaques within the truncus brachiocephalic artery were significantly larger in $\mathrm{HGHCi}$ mice compared to $\mathrm{HCi}$ mice at both study time points (Figure 2E, F).

Less stable plaque phenotypes in hyperglycemia and hyperlipidemia ( $\mathrm{HGHCi}$ versus

\section{hyperlipidemic $(\mathrm{HCi})$ mice}

In addition to plaque size, plaque stability is an important determinant of clinical outcome. We therefore evaluated parameters of plaque stability, in $\mathrm{HCi}$ and $\mathrm{HGHCi}$ mice. Indeed, signs of plaque instability were more pronounced in $\mathrm{HGHCi}$ mice than in $\mathrm{HCi}$ mice as evident from an increased necrotic core area and thinner fibrous caps of HGHCi mice (Figure 2G-I). Plaque morphology and stability depend in part on the cellular composition of plaques. Smooth muscle cells decreased within plaques of $\mathrm{HGHCi}$ mice after 20 weeks compared to $\mathrm{HCi}$ mice (Figure 3A, B). The content of macrophages, that were identified immunohistochemically by MOMA-2 staining was increased in plaques of truncus brachiocephalic artery (Figure $3 \mathrm{C}$ ) of $\mathrm{HGHCi}$ mice in comparison to $\mathrm{HCi}$ mice, both after 12 and 20 weeks. Taken together the observed shift to increased macrophage and reduced SMC and collagen content indicates that plaque stability is reduced in $\mathrm{HGHCi}$ mice[19, 20]. 
Identification of $\mathrm{HGHCi}$-specific transcriptional responses in the aorta

We next aimed to identify transcriptional signatures that are engaged in the vasculature by combined chronic hyperlipidemia and hyperglycemia to generate hypotheses about signaling pathways contributing to larger but unstable plaques in $\mathrm{HGHCi}$ mice. To this end we conducted unbiased gene expression analyses (RNAseq) in the cohorts of control, $\mathrm{HCi}$ and $\mathrm{HGHCi}$ mice at 12 weeks. In aortic tissue of $\mathrm{HCi}$ mice, the expression of 942 genes was induced compared to controls from mice solely on a HFD (Figure 4A). Conversely, gene expression in the aorta of $\mathrm{HGHCi}$ mice was strikingly different from that of $\mathrm{HCi}$ mice. Gene expression of a large set of genes was dysregulated in $\mathrm{HGHCi}$ mice. Thus, in aortic tissue of $\mathrm{HGHCi}$ mice, the expression of 2759 genes was induced compared to aortic samples of saline treated HFD fed mice (Figure 4A). 418 genes showed similar expression in both $\mathrm{HGHCi}$ and $\mathrm{HCi}$ mice, a differential regulation of 2341 genes could be specifically assigned to combined hyperglycemia and hyperlipidemia.

We next performed functional annotation analysis to study the gene pathways that are specifically engaged in the vessels of the $\mathrm{HGHCi}$ group, and observed that combined hyperglycemia plus hyperlipidemia lead to significant changes in the expression of genes encoding signaling molecules involved in inflammation, intracellular lipid transport, cholesterol metabolic processes, collagen degradation, and cellular metabolism (Figure 4B). We further performed gene ontology analysis on genes that were induced in aortic tissue of $\mathrm{HCi}$ and HGHCi mice. Gene ontology analysis of differentially expressed genes revealed that combined hyperglycemia and hyperlipidemia leads to upregulation of genes involved in inflammatory response and collagen degradation (Figure 4C, D).

Paigen diet accentuates atherosclerosis and promotes plaque instability in mice with combined hyperglycemia and hyperlipidemia on paigen diet

We next tested the atherosclerosis model following induction of combined hyperglycemia and hyperlipidemima ( $\mathrm{HGHCi}$ ) in mice fed with a Paigen diet (PD), which leads to higher plasma cholesterol levels [7] and, thus, might further accelerate the formation of atherosclerotic plaques. PD fed mice were treated with the same batch and dose of rAAV8-PCSK9D377Y , and $\mathrm{LDLR}^{-1-}$ mice on PD served as reference for the comparison, saline-injected mice fed on PD served as control for the rAAV8-PCSK9D377Y intervention. Hyperlipidemic and hyperlipidemic plus hyperglycemic mice on PD are for simplicity hereafter called as $\mathrm{HCi}$ - PD and HGHCi- PD mice, respectively. In HGHCi- PD mice, we observed an increased mortality (25\% in week 8, i.e. 5 out of 20 mice died in this group) (Supplementary Figure I, A). Based on these incidences, it was decided that the remaining animals in this group should be sacrificed and analysed already 8- 9 weeks after induction of combined hypercholesterolemia and hyperglycemia, since the 12 and 20 weeks time points chosen for the HGHCi group on HFD 
might not have been reached. Thus, mice from all groups on the PD diet were euthanized 8-9 weeks after rAAV8-PCSK9D377Y injection to quantify atherosclerosis (Figure 5A). Hepatic LDL receptor protein expression was already abrogated at this time point as compared with saline injected mice (control) (Figure 5B, C). As expected, body weight (Supplementary Table 1), plasma cholesterol levels and blood glucose levels differed among treatment groups (Figure 5D-F). In a preliminary pilot study, we compared plasma cholesterol levels of a HGHCi-PD group with STZ-treated mice (STZ-PD) and citrate-treated controls (citrate-PD) fed with Paigen diet, respectively (Supplementary Figure 4). Notably, mice with STZ-evoked hyperglycemia and on a high-cholesterol, high-fat Paigen diet (without AAV-mPCSK9 treatment) did not exhibit an increase in plasma cholesterol (Supplementary Figure 4). Application of the Paigen diet accelerated atherosclerosis in both $\mathrm{HGHCi}-\mathrm{PD}$ and $\mathrm{HCi}$-PD mice compared to corresponding groups on HFD diet $(p<0.05)$. Interestingly, aortic root plaque sizes of HGHCiPD and HCi-PD mice at 8 weeks (Figure 5G-J) were comparable to HGHCi and HCi mice on HFD at 20 weeks, respectively (Figure 2A). Consistent with data from the HFD diet groups, signs of plaque instability were more pronounced in HGHCi-PD mice than in HCi-PD mice as measured by decreased collagen deposition (picro sirus red staining) and increased plaque macrophages content (CD68-positive cells) in plaques of HGHCi-PD mice in comparison with HCi-PD mice (Figure 6A-D). Taken together these data suggest that PD accelerates atherosclerosis in mice and shows plaque formation already after 8 weeks, therefore, representing a fast and direct inducible diabetic atherosclerosis model.

\section{Discussion}

The most frequently used models to study diabetes mellitus associated accelerated atherosclerosis in mice are relying on genetically modified models. Thus, mouse studies evaluating diabetes-associated atherosclerosis rely on $\mathrm{ApoE}^{-/-}$or $\mathrm{LDLR}^{-/-}$mice, where hypercholesterolemia is combined with chronic hyperglycemia following beta cell destruction by injection of streptozotocin (STZ) or viral infection[21] or by cross-breeding with mouse strains carrying a point mutation in the gene encoding insulin leading to a misfolding of the proinsulin 2 protein (Ins2 ${ }^{+} /$Akita)[4, 22]. Induction of hyperglycemia with STZ lead to higher plasma cholesterol levels and show significant acceleration of atherosclerotic lesion formation in $\mathrm{ApoE}^{-/-}$and $\mathrm{LDLR}^{-/-}$mice compared to non-diabetic ApoE ${ }^{-/-}$and $\mathrm{LDLR}^{-/-}$controls[6, 23-29]. Also the severe hyperglycemia in Ins2 $/$ /Akita mice cross-bred with $\mathrm{ApoE}^{-/-}$and LDLR ${ }^{-/-}$leads to a pronounced increase in atherosclerosis and non-HDL cholesterol and triglyceride levels compared to non-hyperglycemic control mice[4, 30, 31]. Although these genetic models are useful tools for studying diabetic complications, it requires intensive cross-breading of these mouse lines. This becomes even more laborious and time consuming when diabetic long-term complications are to be induced in knockout mouse lines for evaluation of the causal role of 
451 the gene of interest under certain metabolic conditions. Concomitant induction of both

452 hypercholesterolemia and hyperglycemia at discrete time points in a given mouse line has not

453 been reported.

454 Here, we describe a novel strategy to induce an atherosclerosis model aggravated by concomitant induction of hyperglycemia without the necessity of genetic germline engineering but via rAAV8-mediated gene transfer of mutant PCSK9 ${ }^{\mathrm{D} 37 Y}$ in hepatocytes in combination with STZ-evoked beta cell destruction ( $\mathrm{HGHCi}$ ). Comparison of plasma cholesterol levels shows increased cholersterol levels in the $\mathrm{HCi}$ model, which increase further by additional induction of hyperglycemia in the HGHCi model. The additional increase in cholesterol levels is a consequence of the two-hit model, because induction of hyperglycemia alone does not increase plasma cholesterol levels. The increased plasma cholesterol levels in the diabetic mice (HGHCi group) are part of the phenotype of our model and resemble findings in previous studies $^{7,26,29,28}$. Dyslipidaemia aggravated by hyperglycaemia is independent of whether the diabetes was induced by STZ injection or genetically (e.g., InsAkita mutant mice). Increased cholesterol levels in the diabetic mice most likely reflect decreased lipoprotein clearance and as such may reflect an important feature of diabetes associated dyslipidaemia. Thus, Goldberg et al. demonstrated that plasma cholesterol levels of STZ- induced diabetic LDLR ${ }^{-/-}$mice were twice those of nondiabetic control mice. The authors observed an increase in both VLDL and LDL. VLDL in plasma was more enriched in cholesterol, and both VLDL and LDL had higher levels of ApoE [29]. Further lipidomics analyses are required to define the lipid profile in diabetic and non-diabetic mice with PCSK9D377Y induced dyslipidaemia. Furthermore, we show that combined hyperlipidemia and hyperglycemia lead to a significant acceleration and enhancement of atherosclerotic plaque formation compared to mice in which hypercholesterolemia was induced without hyperglycemia ( $\mathrm{HCi})$. The $\mathrm{HCi}$ model in rAAV8mediated mutant PCSK9D377Y expressing mice leads to down-regulation of hepatic LDL receptor expression and the development of atherosclerotic lesions. The lesion phenotypes closely resemble those in the established LDL-receptor knockout mouse model. Mice of the $\mathrm{HGHCi}$ treatment group displayed larger plaques compared to norrmoglycemic $\mathrm{HCi}$ mice on the same diet. The treatment induced systemic atherosclerosis, e.g. in the aortic roots and in the brachiocephalic artery. The plaque phenotypes induced by $\mathrm{HGHCi}$ compared to $\mathrm{HCi}$ mice are characterized by increased necrotic core area, decreased fibrous cap thickness and increased frequency of rupture shoulder. Plaques are characterized by increased macrophages and reduced smooth muscle cell content. These data show that the novel HGHCi model provides the prerequisites to study interventions aiming to improve plaque size and importantly - plaque stability.

486 Similar severity of atherosclerosis was observed on Paigen fed diet albeit much earlier, 8 
of cholate in combination with high-cholesterol and high-fat content in Paigen diet boost hypercholesterolemia by facilitating fat and cholesterol absorption resulting in very early fatty streak lesions in the aortic root and proximal aorta in C57BL/6 mice[32]. Thus, our findings are in line with previous work in genetic models, demonstrating that hyperglycemia promotes unstable plaques in both $\mathrm{ApoE}^{-/-}$or LDLR ${ }^{-/-}$mice[14, 33-35]. Our results identify the HGHCiPD model using Paigen diet as novel option for specific experimental set-ups where a very rapid induction of atherosclerosis is needed.

Our unbiased gene expression analysis revealed that combined hyperlipidemia and hyperglycemia $(\mathrm{HGHCi})$ dysregulates a large set of genes (i.e. 2341 genes) in the atherosclerotic aorta compared to hyperlipidemia alone $(\mathrm{HCi})$. The aortic tissue gene expression profile of $\mathrm{HGHCi}$ mice fed a HFD differed markedly from $\mathrm{HCi}$ mice. Among the pathways that were most prominently affected were inflammation, metabolism and particularly immunometabolism, and collagen degradation.

These findings are reminiscent to previous studies, demonstrating that dysregulated immunometabolism promotes diabetes-associated acceleration of atherosclerosis[33, 36]. The increased expression of genes related to collagen degradation is consistent with previous finding showing glucose-induced advanced glycation end products (RAGE) mediate modification of the components of the extracellular matrix and accelerates atherosclerosis under diabetic conditions[37-40]. The expression data may provide a helpful resource for researchers using this model and suggest that this non-genetic model will be suitable to study important aspects of the emerging cross-talk between inflammatory signalling, glucose- and lipoprotein metabolism[22, 41-43].

The study has some limitations. The aim of the study was to develop and to characterize novel models of hyperlipidemia and hyperglycemic associated atherosclerosis. Plasma lipid levels were not identical between groups. Due to the study design, a cohort with only STZ injection was not included as hyperglycemia induced by STZ treatment or lymphocytic choriomeningitis virus (LCMV) infection alone is not sufficient to induce atherosclerosis development in mice[28, 33]. Hence, conclusion about an impact of isolated hyperglycaemia atherosclerotic plaque phenotype cannot be drawn from the current study.

\section{Conclusion}

We describe a novel non-genetic inducible mouse model using a defined treatment with gainof-function PCSK9 viral particles, streptozotocin and high-fat diets. The detailed characterization of the plaques phenotypes and the expression analysis indicate that this new experimental approach can be used to study the clinically important pathogenesis of atherosclerosis in hyperglycemia and hyperlipidemia, and can be induced at any given time 
point to prevent or to therapeutically interfere with the development of atherosclerosis under diabetic conditions.

\section{Acknowledgement}

We thank Sonja Talmon, Beate Hilbert, Christin Richter, Manuela Ritzal, Anja Barnikol-Oettler, and Kathrin Deneser for excellent technical support. We certify that all persons who have made substantial contributions to the manuscript, but who do not fulfill authorship criteria, are named in the acknowledgments section and have provided the corresponding author with written permission to be named in the manuscript.

\section{Authors Contribution:}

S.G., K.S. and R.M., interpreted the experimental work and prepared the manuscript. A.W., R.M., S.G., I.G. and D.S. performed and conducted the in vivo experiments; S.G., I.G., and C.M., performed histological analyses and figure preparation; J.H., J.B., and H.K. performed RNAseq analysis; S.A. and S.F. assisted in histology. B.I. and U. L. interpreted the data and assisted in manuscript preparation. M.F. designed the study and assisted in manuscript preparation.

\section{Sources of Funding}

This work was supported by grants of the 'Deutsche Forschungsgemeinschaft' (including project S03 of the Collaborative Research Centers (SFB) SFB1118 (MF), and IS-67/5-3, IS67/8-1, IS-67/11-1, and CRC854/B26 to B.I., SH 849/4-1 to K.S.

\section{Disclosures}

The authors have nothing to disclose.

\section{References}

[1] Correction to: Heart Disease and Stroke Statistics-2019 Update: A Report From the American Heart Association. Circulation 2020;141(2):e33.

[2] Raghavan S, Vassy JL, Ho Y-L, Song RJ, Gagnon DR, Cho K et al. Diabetes MellitusRelated All-Cause and Cardiovascular Mortality in a National Cohort of Adults. Journal of the American Heart Association 2019;8(4):e011295.

[3] Fang M, Wang D, Coresh J, Selvin E. Trends in Diabetes Treatment and Control in U.S. Adults, 1999-2018. The New England journal of medicine 2021;384(23):2219-28. 
[4] Jun JY, Ma Z, Segar L. Spontaneously diabetic Ins2+/Akita:apoE-deficient mice exhibit exaggerated hypercholesterolemia and atherosclerosis. American Journal of PhysiologyEndocrinology and Metabolism 2011;301(1):E145-E154.

[5] Voyiaziakis E, Goldberg IJ, Plump AS, Rubin EM, Breslow JL, Huang LS. ApoA-I deficiency causes both hypertriglyceridemia and increased atherosclerosis in human apoB transgenic mice. Journal of lipid research 1998;39(2):313-21.

[6] Keren P, George J, Keren G, Harats D. Non-obese diabetic (NOD) mice exhibit an increased cellular immune response to glycated-LDL but are resistant to high fat diet induced atherosclerosis. Atherosclerosis 2001;157(2):285-92.

[7] Bjorklund MM, Hollensen AK, Hagensen MK, Dagnaes-Hansen F, Christoffersen C, Mikkelsen JG et al. Induction of atherosclerosis in mice and hamsters without germline genetic engineering. Circulation research 2014;114(11):1684-9.

[8] Goettsch C, Hutcheson JD, Hagita S, Rogers MA, Creager MD, Pham T et al. A single injection of gain-of-function mutant PCSK9 adeno-associated virus vector induces cardiovascular calcification in mice with no genetic modification. Atherosclerosis 2016;251:109-18.

[9] Grieger JC, Choi VW, Samulski RJ. Production and characterization of adeno-associated viral vectors. Nature protocols 2006;1(3):1412-28.

[10] Zolotukhin S, Byrne BJ, Mason E, Zolotukhin I, Potter M, Chesnut K et al. Recombinant adeno-associated virus purification using novel methods improves infectious titer and yield. Gene Therapy 1999;6(6):973-85.

[11] Jungmann A, Leuchs B, Rommelaere J, Katus HA, Müller OJ. Protocol for Efficient Generation and Characterization of Adeno-Associated Viral Vectors. Human gene therapy methods 2017;28(5):235-46.

[12] Ishibashi S, Goldstein JL, Brown MS, Herz J, Burns DK. Massive xanthomatosis and atherosclerosis in cholesterol-fed low density lipoprotein receptor-negative mice. The Journal of clinical investigation 1994;93(5):1885-93.

[13] Zhou Q, Bea F, Preusch M, Wang H, Isermann B, Shahzad K et al. Evaluation of Plaque Stability of Advanced Atherosclerotic Lesions in Apo E-Deficient Mice after Treatment with the Oral Factor Xa Inhibitor Rivaroxaban. Mediators of Inflammation 2011;2011:432080.

[14] Shahzad K, Gadi I, Nazir S, Al-Dabet M'dM, Kohli S, Bock F et al. Activated protein C reverses epigenetically sustained $p 66^{\text {shc }}$ expression in plaque-associated macrophages in diabetes. Communications biology 2018;1:104.

[15] Seehaus S, Shahzad K, Kashif M, Vinnikov IA, Schiller M, Wang $H$ et al. Hypercoagulability inhibits monocyte transendothelial migration through proteaseactivated receptor-1-, phospholipase-Cbeta-, phosphoinositide 3-kinase-, and nitric oxide- 
dependent signaling in monocytes and promotes plaque stability. Circulation 2009;120(9):774-84.

[16] Shahzad K, Thati M, Wang H, Kashif M, Wolter J, Ranjan S et al. Minocycline reduces plaque size in diet induced atherosclerosis via p27(Kip1). Atherosclerosis 2011;219(1):74-83.

[17] Schuster S, Rubil S, Endres M, Princen HMG, Boeckel J-N, Winter K et al. Anti-PCSK9 antibodies inhibit pro-atherogenic mechanisms in APOE*3Leiden.CETP mice. Scientific reports 2019;9(1):11079.

[18] Gaul S, Leszczynska A, Alegre F, Kaufmann B, Johnson CD, Adams LA et al. Hepatocyte pyroptosis and release of inflammasome particles induce stellate cell activation and liver fibrosis. Journal of Hepatology.

[19] Harman JL, Jørgensen HF. The role of smooth muscle cells in plaque stability: Therapeutic targeting potential. British journal of pharmacology 2019;176(19):3741-53.

[20] Doran AC, Meller N, McNamara CA. Role of smooth muscle cells in the initiation and early progression of atherosclerosis. Arteriosclerosis, thrombosis, and vascular biology 2008;28(5):812-9.

[21] SHEN XIA, BORNFELDT KE. Mouse Models for Studies of Cardiovascular Complications of Type 1 Diabetes. Annals of the New York Academy of Sciences 2007;1103(1):202-17.

[22] Oppi S, Lüscher TF, Stein S. Mouse Models for Atherosclerosis Research-Which Is My Line? Frontiers in Cardiovascular Medicine 2019;6:46.

[23] Tse J, Martin-McNaulty B, Halks-Miller M, Kauser K, DelVecchio V, Vergona R et al. Accelerated atherosclerosis and premature calcified cartilaginous metaplasia in the aorta of diabetic male Apo $\mathrm{E}$ knockout mice can be prevented by chronic treatment with $17 \beta$ estradiol. Atherosclerosis 1999;144(2):303-13.

[24] Vikramadithyan RK, Hu Y, Noh H-L, Liang C-P, Hallam K, Tall AR et al. Human aldose reductase expression accelerates diabetic atherosclerosis in transgenic mice. The Journal of clinical investigation 2005;115(9):2434-43.

[25] Lewis P, Stefanovic N, Pete J, Calkin AC, Giunti S, Thallas-Bonke V et al. Lack of the Antioxidant Enzyme Glutathione Peroxidase-1 Accelerates Atherosclerosis in Diabetic Apolipoprotein E-Deficient Mice. Circulation 2007;115(16):2178-87.

[26] Vedantham S, Noh H, Ananthakrishnan R, Son N, Hallam K, Hu Y et al. Human Aldose Reductase Expression Accelerates Atherosclerosis in Diabetic Apolipoprotein E-/- Mice. Arteriosclerosis, thrombosis, and vascular biology 2011;31(8):1805-13.

[27] Park L, Raman KG, Lee KJ, Lu Y, Ferran LJ, Chow WS et al. Suppression of accelerated diabetic atherosclerosis by the soluble receptor for advanced glycation endproducts. Nature Medicine 1998;4(9):1025-31. 
[28] Hammad SM, Hazen-Martin DJ, Sohn M, Eldridge L, Powell-Braxton L, Won W et al. Nephropathy in a Hypercholesterolemic Mouse Model with Streptozotocin-Induced Diabetes. Kidney Blood Press Res 2003;26(5-6):351-61.

[29] Goldberg IJ, Hu Y, Noh H-L, Wei J, Huggins LA, Rackmill MG et al. Decreased lipoprotein clearance is responsible for increased cholesterol in LDL receptor knockout mice with streptozotocin-induced diabetes. Diabetes 2008;57(6):1674-82.

[30] Zhou C, Pridgen B, King N, Xu J, Breslow JL. Hyperglycemic Ins2AkitaLdlr-/- mice show severely elevated lipid levels and increased atherosclerosis: a model of type 1 diabetic macrovascular disease[S]. Journal of lipid research 2011;52(8):1483-93.

[31] Engelbertsen D, To F, Dunér P, Kotova O, Söderberg I, Alm R et al. Increased Inflammation in Atherosclerotic Lesions of Diabetic Akita- $L D L r^{-1}$ Mice Compared to Nondiabetic LDLr ${ }^{-1-}$ Mice. Experimental Diabetes Research 2012;2012:176162.

[32] Getz GS, Reardon CA. Diet and Murine Atherosclerosis. Arteriosclerosis, thrombosis, and vascular biology 2006;26(2):242-9.

[33] Johansson F, Kramer F, Barnhart S, Kanter JE, Vaisar T, Merrill RD et al. Type 1 diabetes promotes disruption of advanced atherosclerotic lesions in LDL receptor-deficient mice. Proceedings of the National Academy of Sciences of the United States of America 2008;105(6):2082-7.

[34] BORNFELDT KE. Uncomplicating the Macrovascular Complications of Diabetes: The 2014 Edwin Bierman Award Lecture. Diabetes 2015;64(8):2689-97.

[35] Renard CB, Kramer F, Johansson F, Lamharzi N, Tannock LR, Herrath MG von et al. Diabetes and diabetes-associated lipid abnormalities have distinct effects on initiation and progression of atherosclerotic lesions. The Journal of clinical investigation 2004;114(5):659-68.

[36] Stitziel NO, Kanter JE, BORNFELDT KE. Emerging Targets for Cardiovascular Disease Prevention in Diabetes. Trends in molecular medicine 2020;26(8):744-57.

[37] Ihara Y, Egashira K, Nakano K, Ohtani K, Kubo M, Koga J-i et al. Upregulation of the ligand-RAGE pathway via the angiotensin II type I receptor is essential in the pathogenesis of diabetic atherosclerosis. Journal of molecular and cellular cardiology 2007;43(4):455-64.

[38] Bu D-x, Rai V, Shen X, Rosario R, Lu Y, D'Agati V et al. Activation of the ROCK1 branch of the transforming growth factor-beta pathway contributes to RAGE-dependent acceleration of atherosclerosis in diabetic ApoE-null mice. Circulation research 2010;106(6):1040-51.

[39] Soro-Paavonen A, Watson AMD, Li J, Paavonen K, Koitka A, Calkin AC et al. Receptor for advanced glycation end products (RAGE) deficiency attenuates the development of atherosclerosis in diabetes. Diabetes 2008;57(9):2461-9. 
[40] Wang Z, Jiang Y, Liu N, Ren L, Zhu Y, An Y et al. Advanced glycation end-product Nعcarboxymethyl-Lysine accelerates progression of atherosclerotic calcification in diabetes. Atherosclerosis 2012;221(2):387-96.

[41] Martins IJ, Hone E, Foster JK, Sünram-Lea SI, Gnjec A, Fuller SJ et al. Apolipoprotein E, cholesterol metabolism, diabetes, and the convergence of risk factors for Alzheimer's disease and cardiovascular disease. Molecular psychiatry 2006;11(8):721-36.

673

[42] Farmer BC, Johnson LA, Hanson AJ. Effects of apolipoprotein E on nutritional metabolism in dementia. Current opinion in lipidology 2019;30(1):10-5.

675

[43] Hui DY, Basford JE. Distinct signaling mechanisms for apoE inhibition of cell migration and proliferation. Neurobiology of aging 2005;26(3):317-23. 
Figures

Figure 1

A

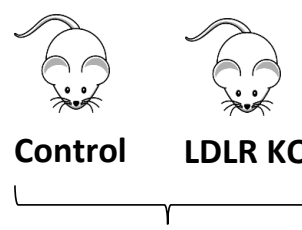

Saline
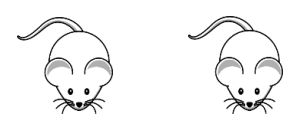

$\mathrm{HCi} \quad \mathrm{HGHCi}$

rAAV8-PCSK9D377Y

High-fat diet (HFD)

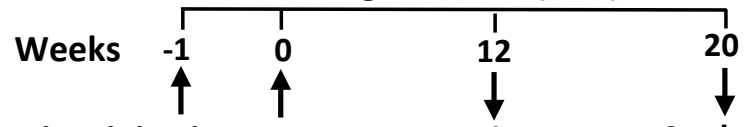

Virus injection Diet Analysis Analysis

$\mathrm{HCi}$ : hyperlipidemic; $\mathrm{HGHCi}$ : hyperglycemic/hyperlipidemic

C

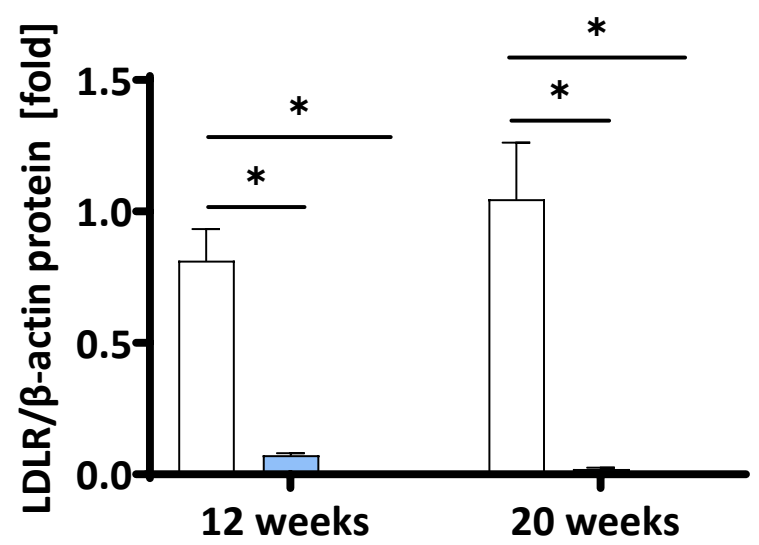

E

בृ

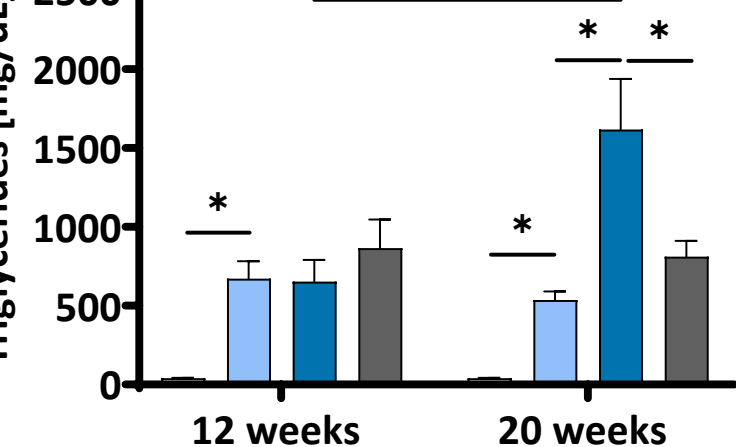

B

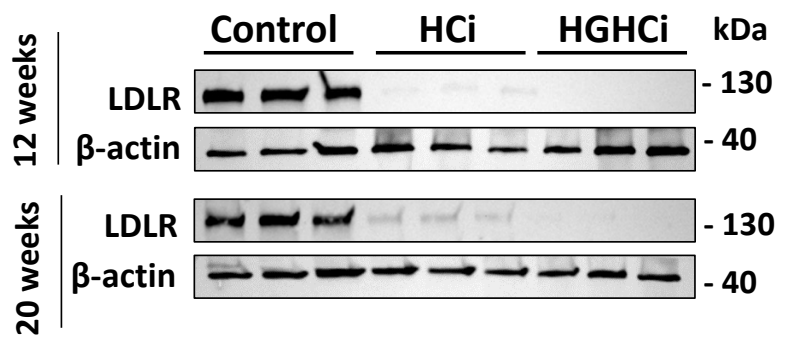

$\square$ Control $\square \mathrm{HGHCi}$

$\mathrm{HCi} \mathrm{LDLR}^{-1}$

D

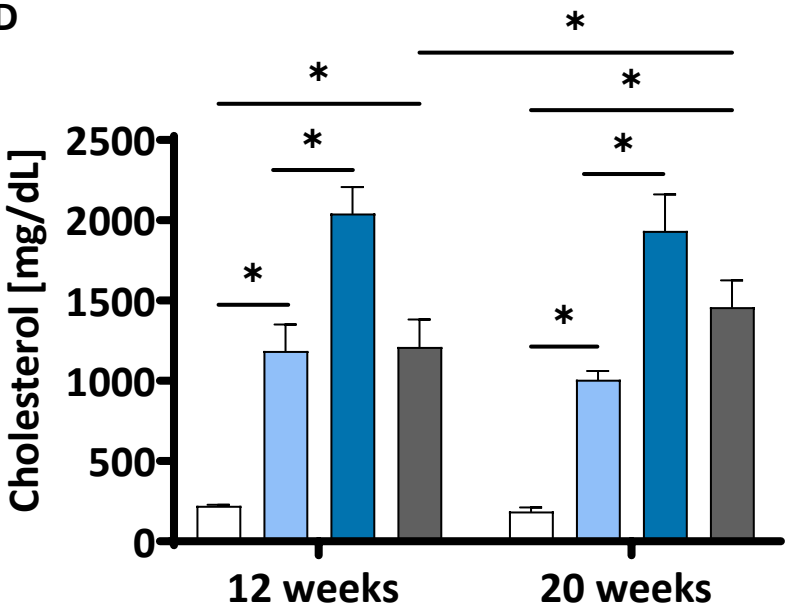

$\mathbf{F}$

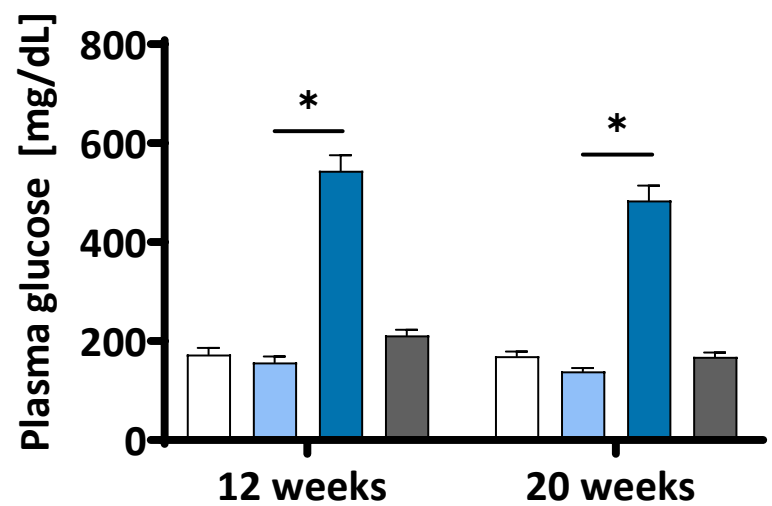


Figure 1: Simultaneous treatment of rAAV8-PCSK9 virus and Streptozotocin induces a hyperlipidemic and hyperglycemic mouse phenotype. A: Schematic summary of the experimental setup. Mice were analyzed after 12 or 20 weeks of interventions initiation. Wild

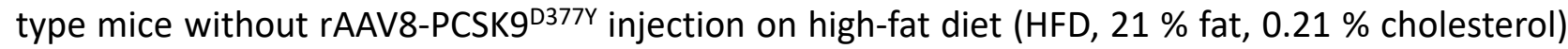
was used as control. Mice injected with rAAV8-PCSK9D377Y and fed a HFD are termed $\mathrm{HCi}$ (hyperlipidemic), or injected with both rAAV8-PCSK9 ${ }^{\text {D377Y }}$ and streptozotocin and fed a HFD are termed HGHCi (hyperlipidemic and hyperglycemic). LDLR-/- mice on HFD served as reference control. B: Representative immunoblot of liver lysate showing hepatic protein levels of lowdensity lipoprotein receptor (LDLR). $\beta$-actin was used as loading control. C: Densitometric analysis of LDLR immunoblot was normalized on $\beta$-actin and referred to control group which is set at 1 . Bar graphs are showing level of D: plasma cholesterol level $[\mathrm{mg} / \mathrm{dL}, \mathrm{E}$ : Triglycerides $[\mathrm{mg} / \mathrm{dL}]$ and F: blood glucose levels $[\mathrm{mg} / \mathrm{dL}]$. Data are presented as mean \pm SEM and one-way ANOVA was performed with Sidak's multiple comparison post-hoc test $\left({ }^{*} p<0.05\right)$. $N=6$ for each group. 
Figure 2

A H \& E
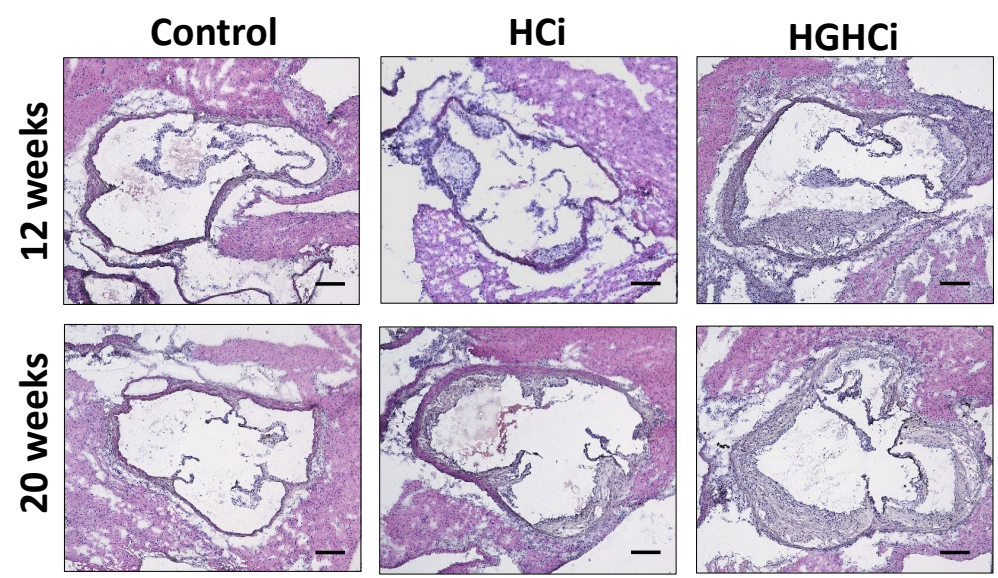

C Oil red 0
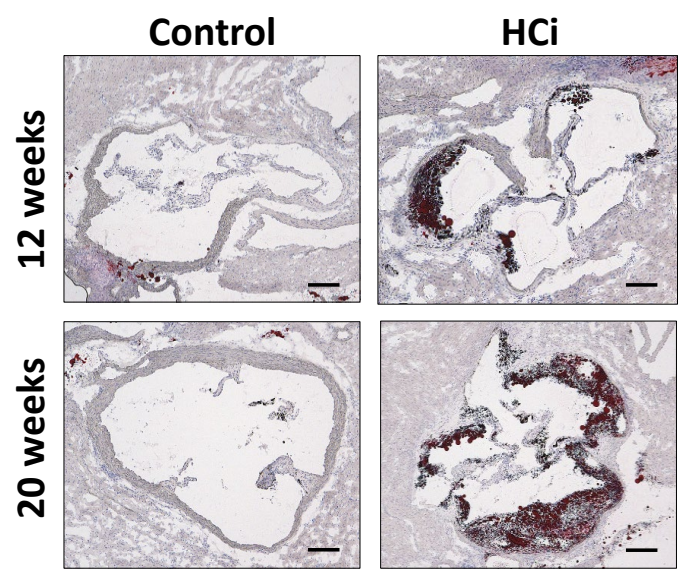

E Oil red 0
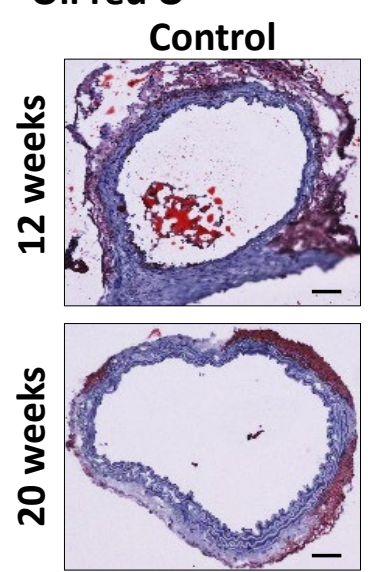

G MOVAT
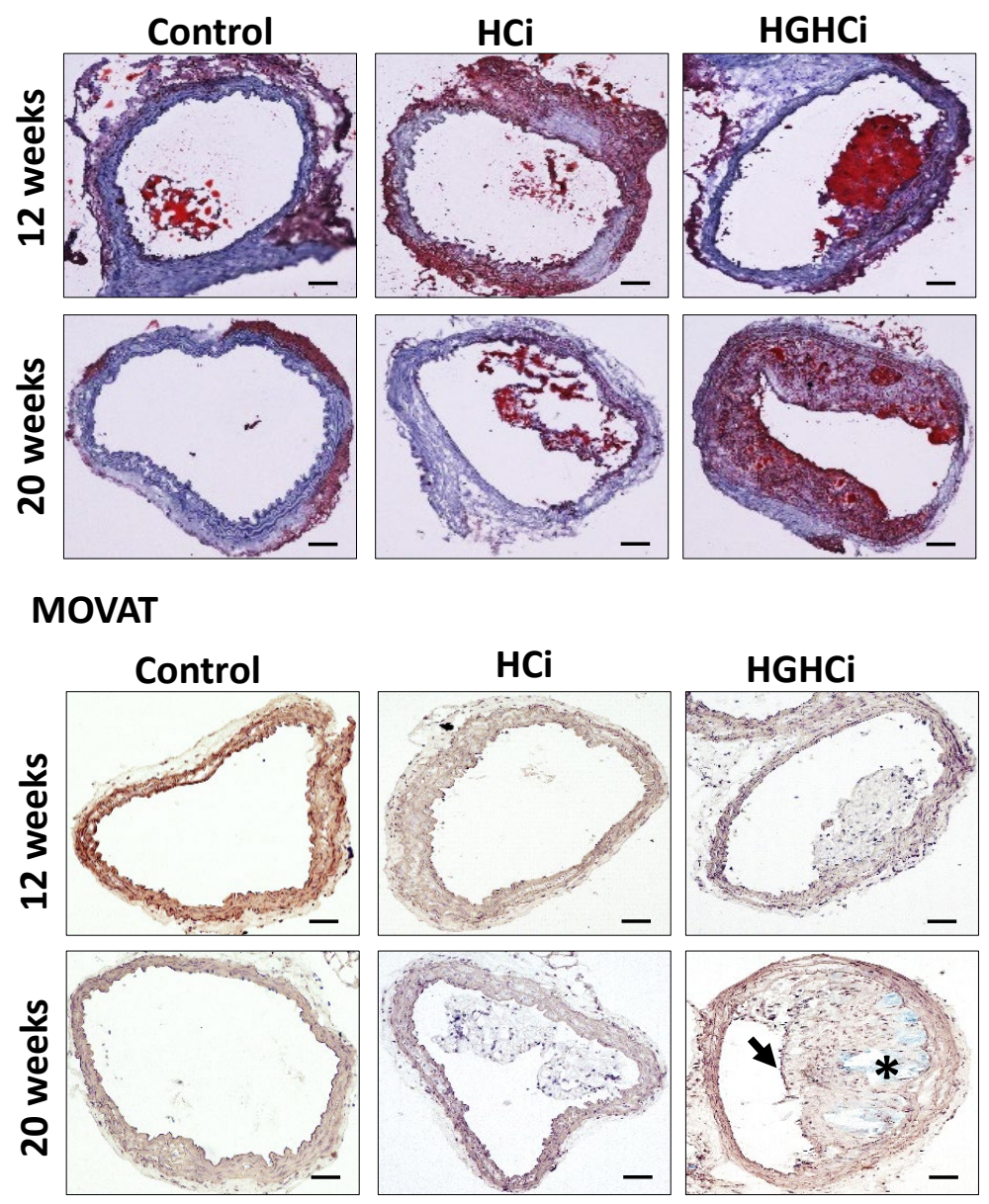

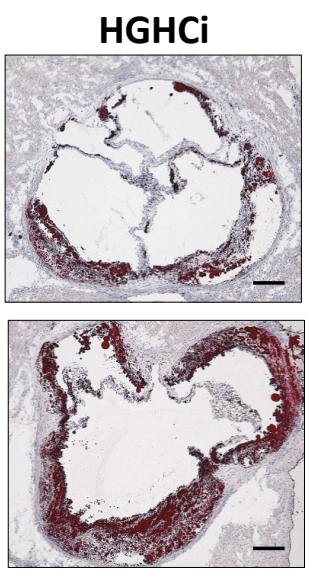

B

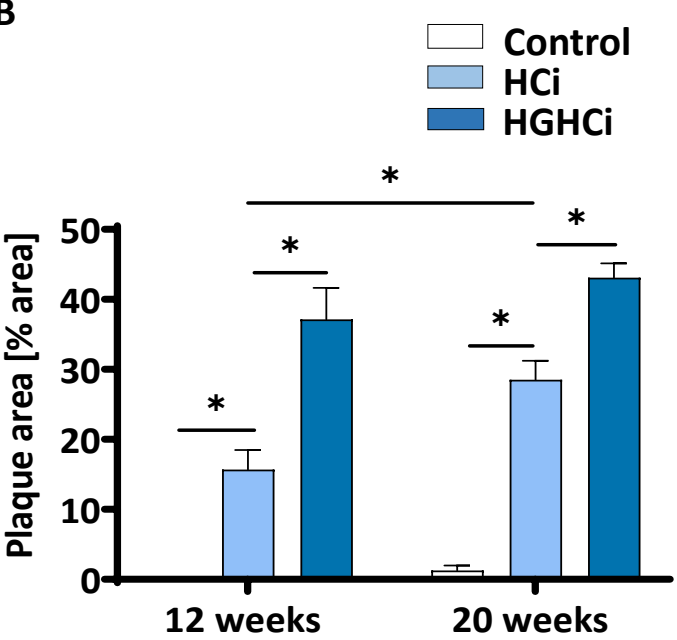

D

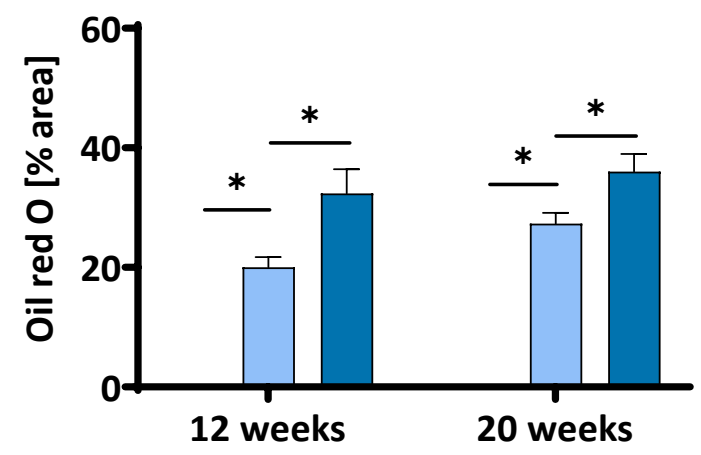

F

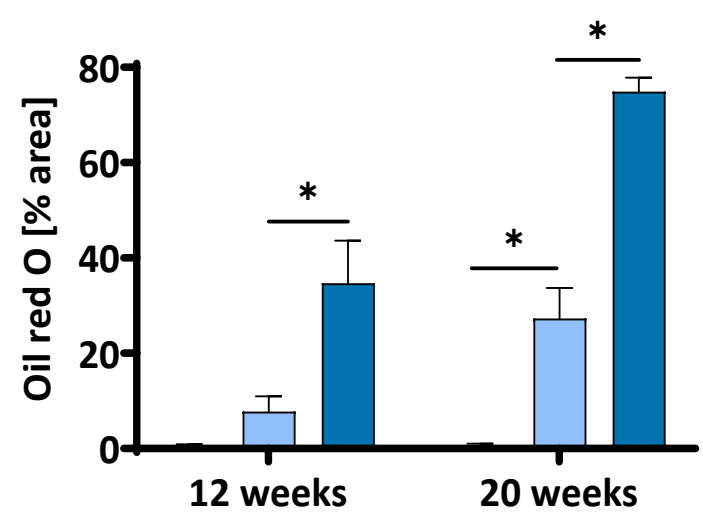

H
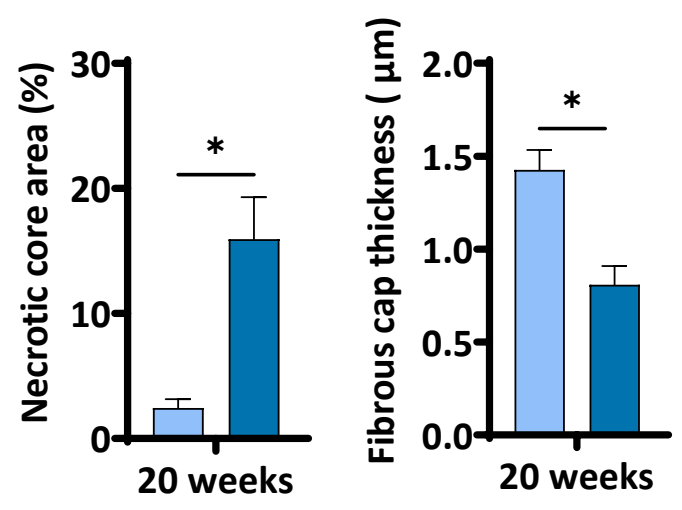
Figure 2: Mice with combined hyperlipidemia and hyperglycemia show larger plaques than hyperlipidemic mice. A-D: Representative histological images showing aortic root sections stained with Hematoxylin/ Eosin ( $H$ \& $E, A)$ and bar graphs summarizing data (B). Representative histological images showing aortic root sections stained with Oil-Red $O$ (C) and bar graphs summarizing data (D). E-H: Representative histological images showing truncus brachiocephalic arteries sections stained with Oil-Red $O(E$,$) and bar graphs summarizing data (F). Representative$ images showing MOVATs pentachrome staining of truncus brachiocephalic arteries (G). Bar graphs summarizing morphometric analyses of MOVATs stained images for necrotic core area $(H)$ and fibrous caps (I). Necrotic core area within plaque is indicated by*, fibrous caps thickness by a black arrow in MOVAT stained truncus brachiocephalic arteries ( $G$, bottom panel). Data presented as mean \pm SEM and one-way ANOVA was performed with Sidak's multiple comparison post-hoc test $(* p<0.05)$. Stainings are imaged at $4 \times$ magnification, scale bar $200 \mu \mathrm{m}(A, C, E, G)$. HFD control 12 and 20 weeks $(N=7), \mathrm{HCi} 12$ and 20 weeks $(\mathrm{N}=5)$, and HGHCi 12 and 20 weeks $(\mathrm{N}=6)$.

Control: Wild type mice without rAAV8-PCSK9D377Y injection on high fat diet (HFD); HCi: rAAV8PCSK9D377Y injection plus HFD (hyperlipidemic); HGHCi: rAAV8-PCSK9D377Y and streptozotocin injection and HFD (hyperlipidemic and hyperglycemic). 
Figure 3

A $\alpha$-SMA

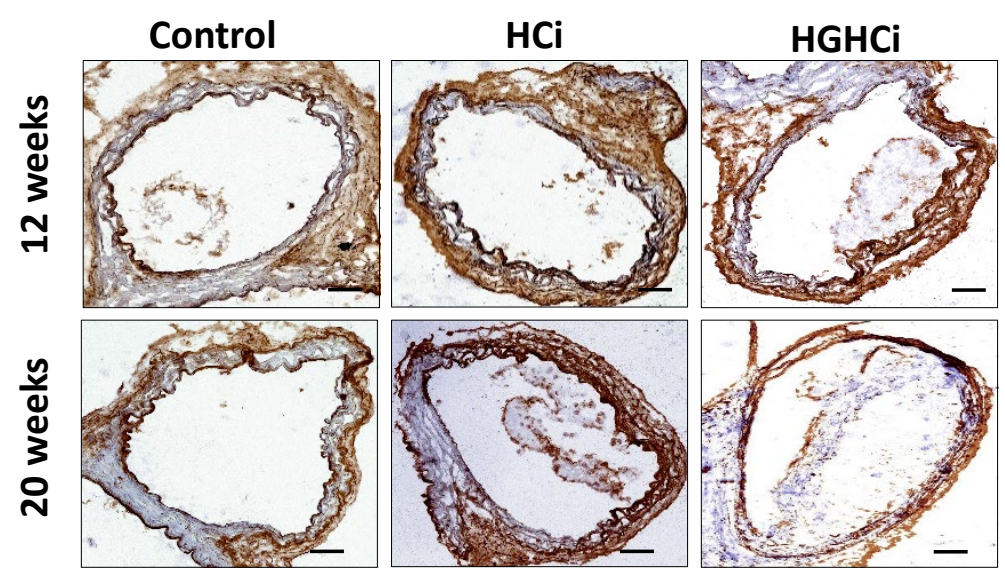

C

MOMA-2
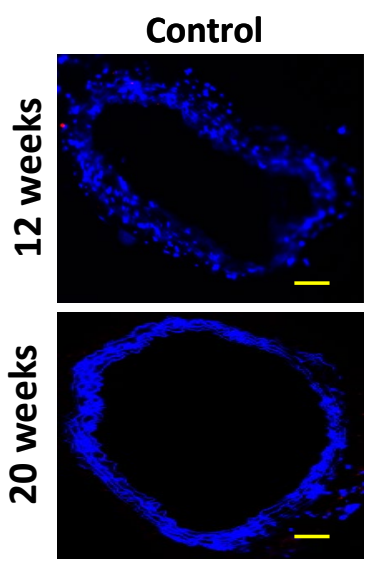

MOMA-2/DAPI
$\mathrm{HCi}$
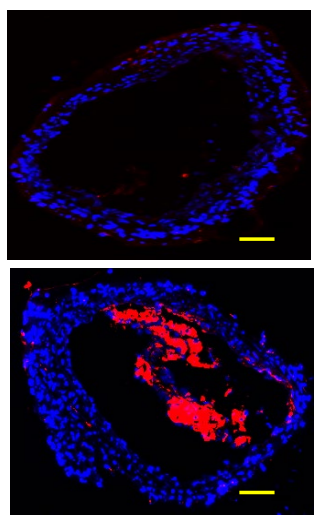

HGHCi
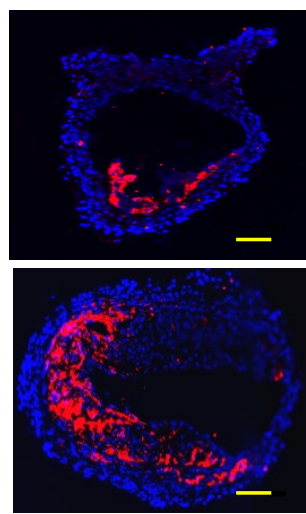

B

Control

$\mathrm{HCi}$

$\mathrm{HGHCi}$

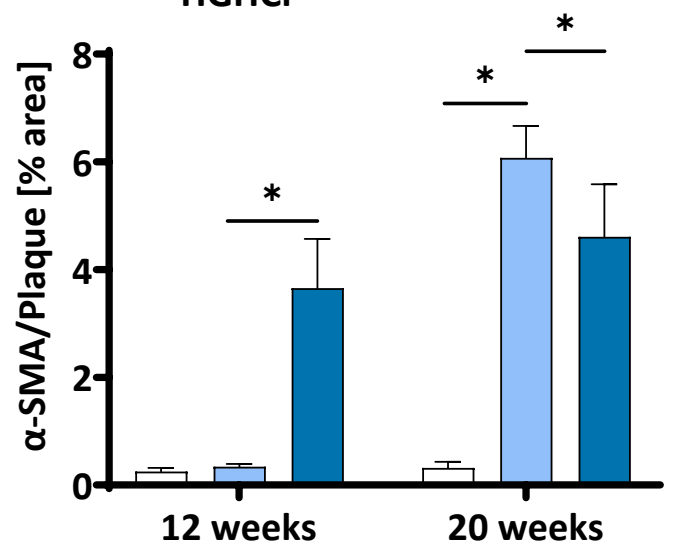

D

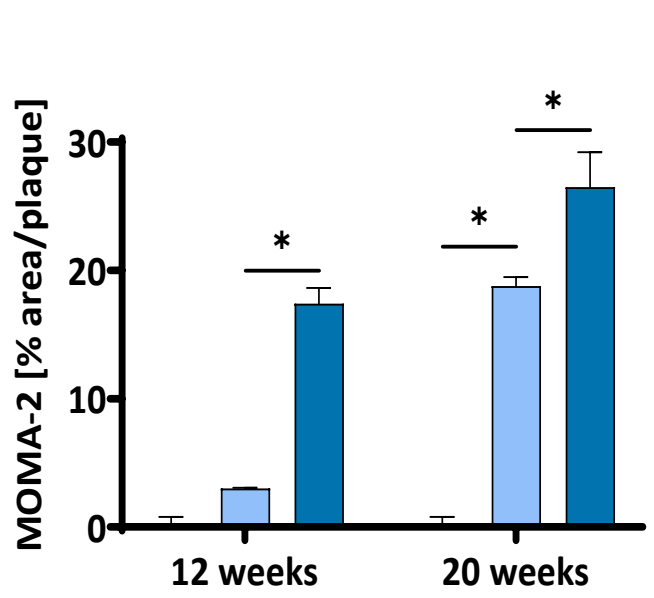


Figure 3: Less smooth muscle cells and collagen content within plaques of hyperlipidemic and hyperglycemic mice as compared to hyperlipidemic mice. A, B: Representative images showing immunohistochemical staining for smooth muscle cell marker $\alpha$-SMA (positive cells detected by HRP-DAB reaction, brown) on truncus brachiocephalic arteries sections ( $\mathbf{A}$, scale bar $200 \mu \mathrm{m})$ and bar graphs summarizing data (B). The data are presented as mean \pm SEM and one-way ANOVA was performed with Sidak's multiple comparison post-hoc test ( $\left.{ }^{*} p<0.05\right)$. C, D: Representative images showing immunofluorescence staining of truncus brachiocephalic arteries sections for macrophages marker MOMA-2 (C, MOMA-2= red; DAPI nuclear counterstain= blue) and bar graphs summarizing data (D). The data are presented as mean \pm SEM and one-way ANOVA was performed with Sidak's multiple comparison post-hoc test $\left({ }^{*} p<0.05\right)$. Scale bar $200 \mu \mathrm{m}$. Control 12 and 20 weeks $(\mathrm{N}=7), \mathrm{HCi} 12$ weeks $(\mathrm{N}=5)$ and 20 weeks $(\mathrm{N}=6), \mathrm{HGHCi} 12$ weeks $(\mathrm{N}=7)$ and 20 weeks $(\mathrm{N}=6)$. Control: Wild type mice without $\mathrm{rAAV8}-\mathrm{PCSK} 9^{\mathrm{D} 377 \mathrm{i}}$ injection on high fat diet (HFD); HCi: rAAV8-PCSK9D377Y injection plus HFD (hyperlipidemic); HGHCi: rAAV8-PCSK9D377Y and streptozotocin injection and HFD (hyperlipidemic and hyperglycemic). 
Enriched differentially expressed genes

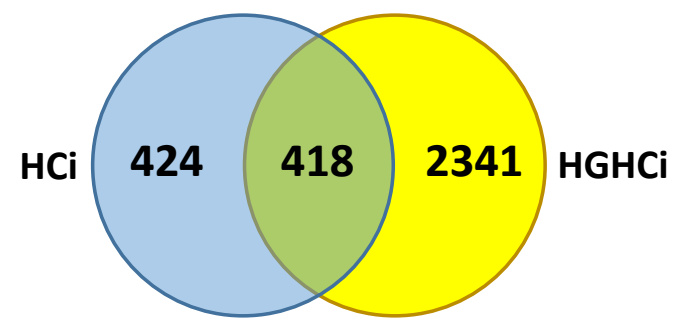

\section{Inflammatory response genes}

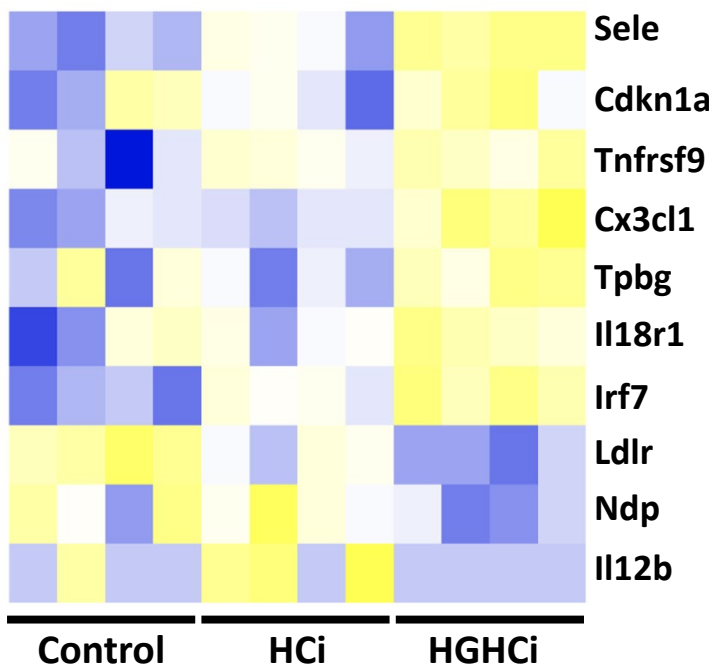

B

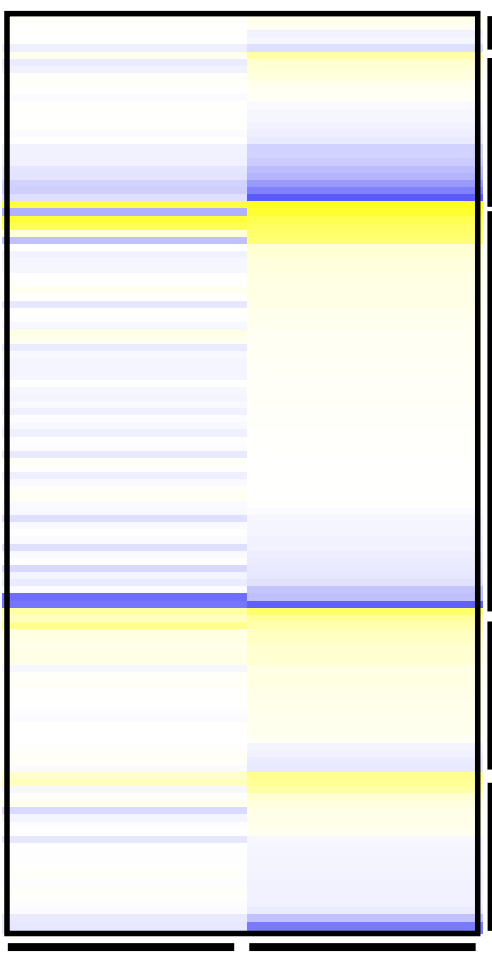

Extracellular Matrix

Degradation

Inflammation

Log2 fold change to control

Metabolism

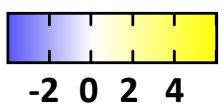

\section{$\mathrm{HCi} \quad \mathrm{HGHCi}$}

D Collagen degradation pathway
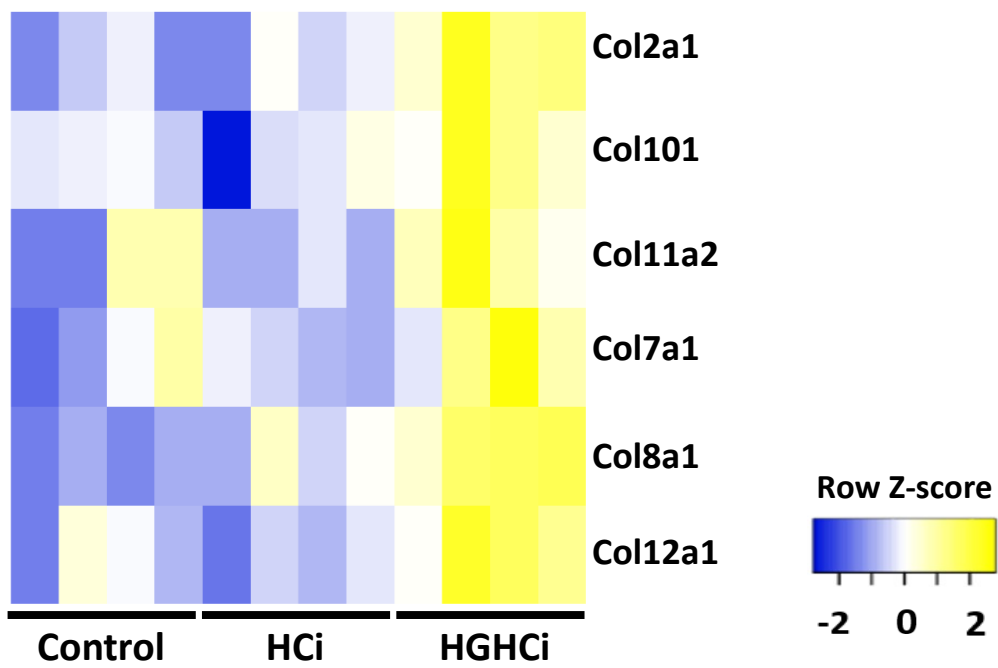

Figure 4: Combined hyperglycemia and hyperlipidemia induce large set of differentially expressed genes and activates inflammatory response and collagen degradation pathways. RNA sequencing in aortic tissue of control, $\mathrm{HCi}$ and $\mathrm{HGHCi}$ mice after 12 weeks. Wild type mice without AAV8-PCSK9D377Y injection on high fat diet (control) or injected with rAAV8-PCSK9 ${ }^{D 377 Y}$ and on HFD (hyperlipidemic, HCi) or injected with both rAAV8-PCSK9D377Y and streptozotocin and fed HFD (hyperlipidemic and hyperglycemic, $\mathrm{HGHCi}$ ). A: Venn diagram showing overlap of genes significantly changed in $\mathrm{HGHCi}$ or $\mathrm{HCi}$ mice in relation to gene expression in control mice. B: Heat map summarizing differentially expressed gene (DEGs) identified by RNA sequencing and DEGs related biological processes using Gene Ontology and EnrichR analysis. Gene count values larger than the average are represented in yellow, while lower counts than the average are represented in blue. Whenever transcript values are close to the control value, samples are colored in white. C, D: Heat maps showing list of DEGs related to inflammatory response and collagen degradation pathways, using Gene Ontology and EnrichR analysis. Gene count values larger than the average control are represented in yellow, while lower counts than the average control are represented in blue. Whenever transcript values are close to the control value, samples are colored in white. 
Figure 5

A

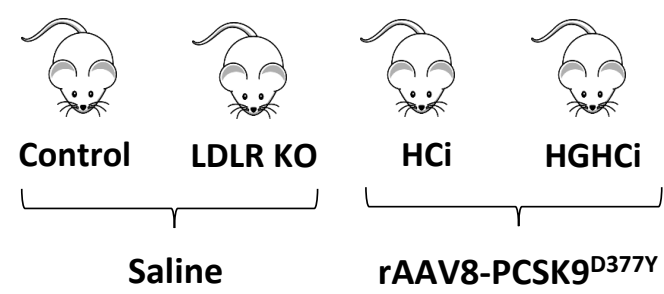

Paigen diet (PD)

Weeks -1

Virus injection Diet

HCi: hyperlipidemic; HGHCi: hyperglycemic/hyperlipidemic
B

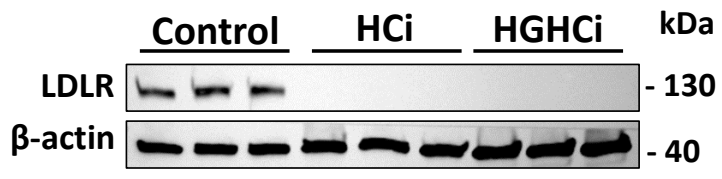

Paigen control

HCi Paigen

HGHCi Paigen

$\mathrm{LDLR}^{-/-}$
C

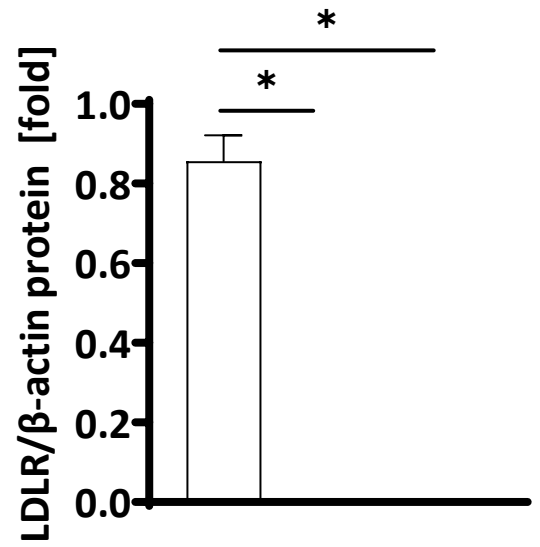

E

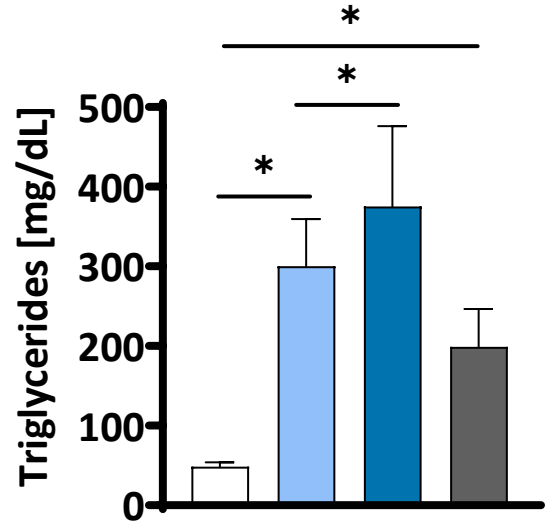

G

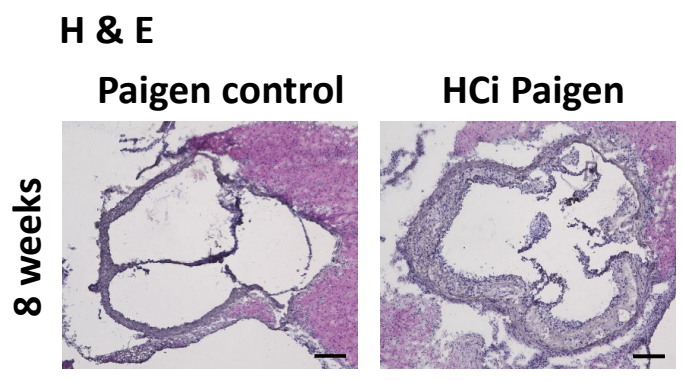

I Oil red 0

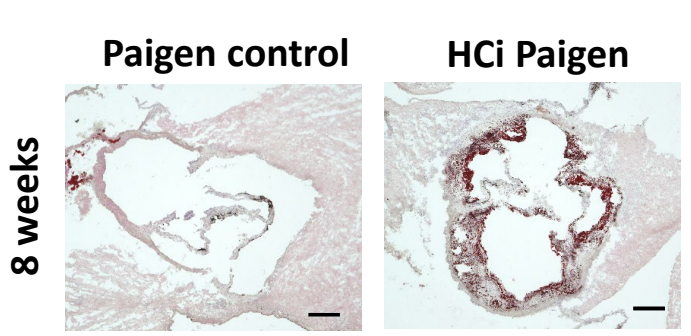

D

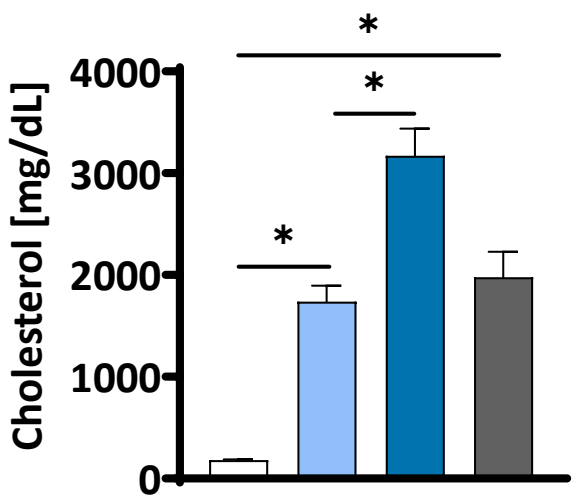

F

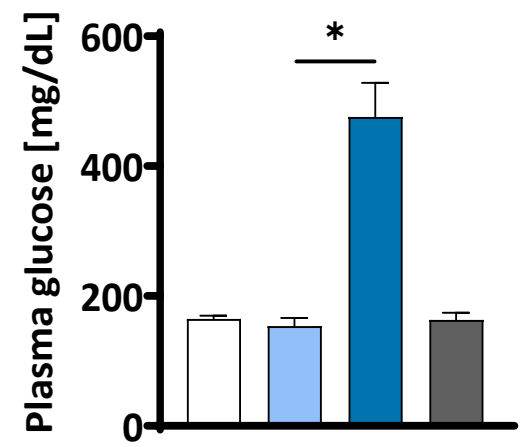

H
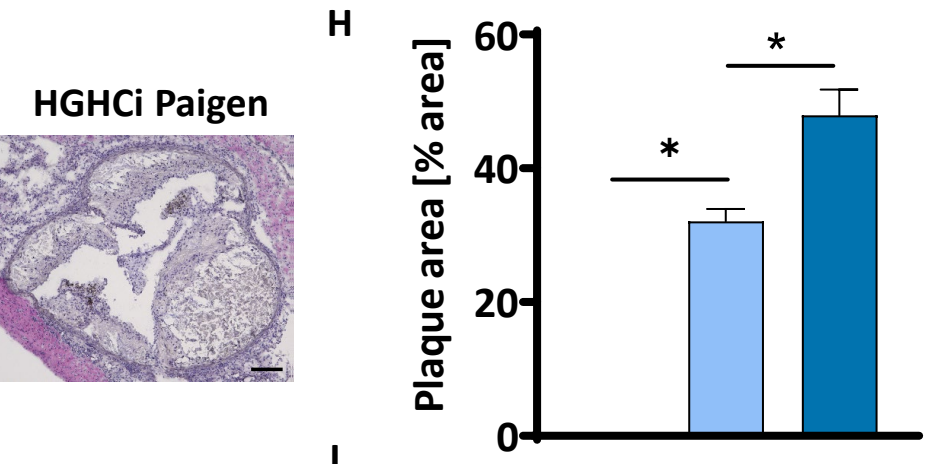

HGHCi Paigen

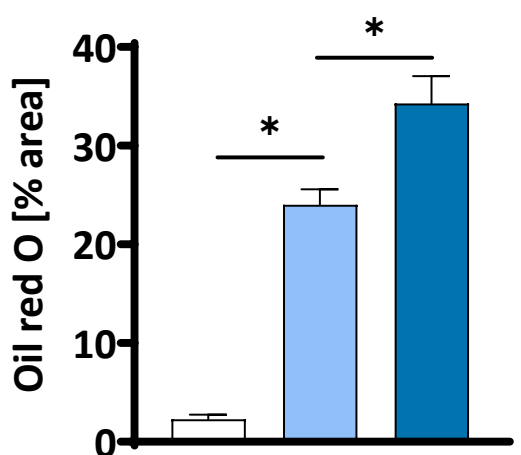


Figure 5: Paigen diet accelerates plaque formation after 8 weeks in the rAAV8-PCSK9 streptozotocin induced hyperglycemic atherosclerosis mouse model. A: Schematic summary of the experimental setup. Mice were analyzed after 8 weeks of interventions initiation. B: Representative immunoblot showing hepatic protein levels of low-density lipoprotein receptor (LDLR). $\beta$-actin was used as loading control and bar graphs summarizing data. Data were normalized on control mice which were set at 1 (C). Bar graphs summarizing data of plasma cholesterol level [mg/dL, D], triglycerides [mg/dL, E), and blood glucose levels [mg/dL, F]. G-J: Representative histological images showing aortic root sections stained with Hematoxylin Eosin (H \& E, G) and bar graphs summarizing data (H). Representative histological images showing aortic root sections stained with Oil-red-O (I) and bar graphs summarizing data (J). Data presented as mean \pm SEM and one-way ANOVA was performed with Sidak's multiple comparison post-hoc test $\left({ }^{*} p<05\right)$. Scale bar $200 \mu \mathrm{m}$. Paigen control $(\mathrm{N}=6)$, HCi Paigen $(\mathrm{N}=6), \mathrm{HGHCi}$ Paigen $(\mathrm{N}=6)$. Control: Wild type mice without rAAV8-PCSK9 ${ }^{D 377 Y}$ injection on paigen diet (PD); HCi Paigen: mice injected with rAAV8-PCSK9 ${ }^{D 377 Y}$ and fed PD (hyperlipidemic); HGHCi Paigen: mice injected with both rAAV8-PCSK9 ${ }^{\text {D377Y }}$ and streptozotocin and fed PD (hyperlipidemic and hyperglycemic). 
A Sirius red

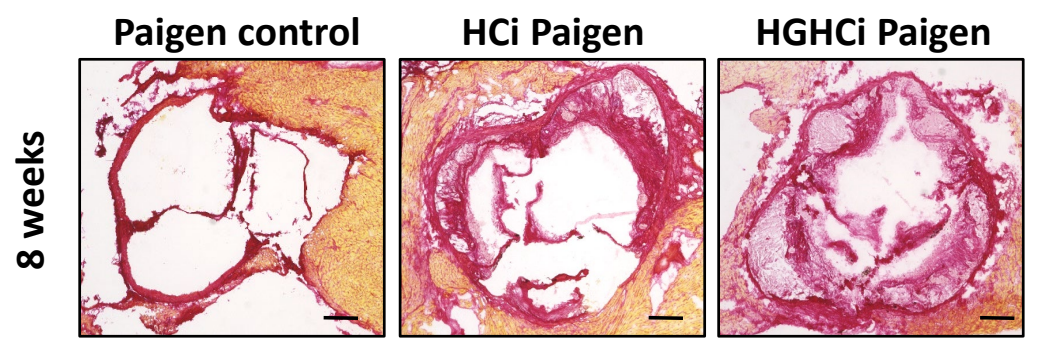

C $\mathbf{C D 6 8}$

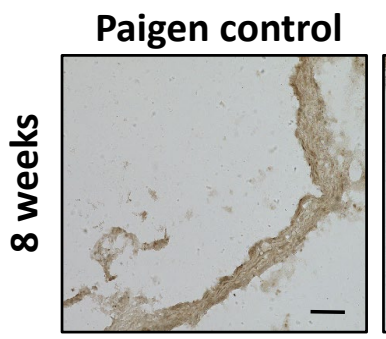

B

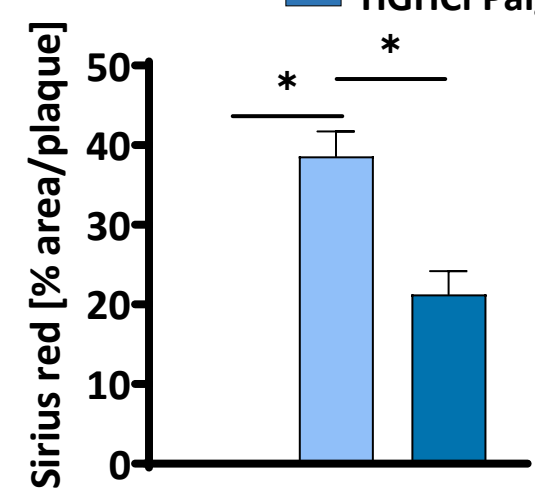

D

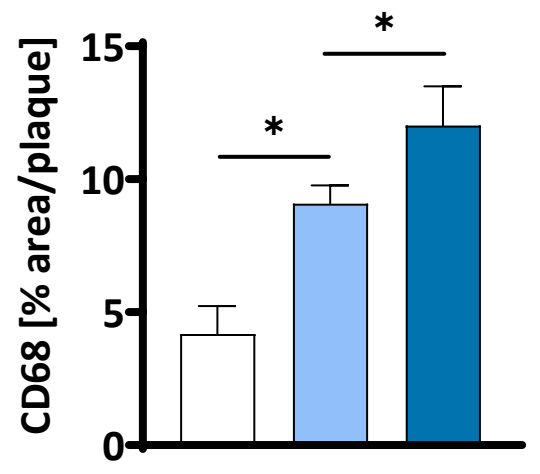

Figure 6: Hyperlipidemic and hyperglycemic mice fed a Paigen diet (PD) show an increased macrophage infiltration within aortic plaques compared to hyperlipidemic mice. A: Representative images showing picrosirius red staining for collagen in aortic root sections nd bar graphs summarizing data (B). Scale bar $200 \mu \mathrm{m}$. C: Representative images showing immunohistochemical staining of aortic root sections for macrophages marker CD68 (positive cells detected by HRP-DAB reaction, brown) and bar graphs summarising data (D). Data presented as mean \pm SEM and one-way ANOVA was performed with Sidak's multiple comparison post-hoc test $(* p<0.05)$. Scale bar $100 \mu \mathrm{m}$. Paigen control $(\mathrm{N}=7), \mathrm{HCi}(\mathrm{N}=4)$, HGHCi Paigen $(\mathrm{N}=4)$. Control Paigen: Wild type mice without rAAV8-PCSK9D377Y injection on paigen diet (PD); HCi Paigen: mice injected with rAAV8-PCSK9D377Y and fed PD (hyperlipidemic, $\mathrm{HCi}$ ); $\mathrm{HGHCi}$ Paigen: mice injected with both rAAV8-PCSK9 ${ }^{D 77 Y}$ and streptozotocin and fed PD (hyperlipidemic and hyperglycemic). 


\section{Supplementary Material}

\section{Content:}

Supplementary Table 1. Characteristics of mice cohort.

Supplementary Figure I. PD fed HGHCi mice showed higher mortality than HFD fed mice.

Supplementary Figure II. Comparison with HFD fed LDLR KO mice.

Supplementary Figure III. Comparison with Paigen fed LDLR KO mice.

Supplementary Figure IV. Hyperglycemia alone does not affect plasma cholesterol levels in mice fed a Paigen diet.

\section{Major resources table}


Supplementary Table 1. Characteristics of mice cohort.

\begin{tabular}{lccc} 
High-fat diet & $\begin{array}{c}\text { Body weight } \\
\text { [g] }\end{array}$ & $\begin{array}{c}\text { Liver weight } \\
\text { [g] }\end{array}$ & $\begin{array}{c}\text { Liver/body weight } \\
\text { ratio }\end{array}$ \\
\hline $\begin{array}{l}\text { 12 weeks } \\
\text { Normal chow }\end{array}$ & $31.8 \pm 3.7^{\mathrm{a}}$ & $1.5 \pm 0.4^{\mathrm{a}}$ & 0.04 \\
Saline HFD & $40.4 \pm 2.3$ & $2.8 \pm 0.5^{2}$ & 0.06 \\
HCi HFD & $39.1 \pm 3.3$ & $2.6 \pm 0.5$ & 0.07 \\
HGHCi HFD & $24.7 \pm 0.9^{\mathrm{b}}$ & $2.8 \pm 0.2$ & 0.11 \\
LDLR KO HFD & $36.3 \pm 5.5$ & $2.1 \pm 0.6$ & 0.05 \\
& & & \\
20 weeks & & $1.7 \pm 0.1^{\mathrm{a}}$ & 0.05 \\
Normal chow & $32.5 \pm 2.8^{\mathrm{a}}$ & $3.0 \pm 1.1^{\mathrm{b}}$ & 0.07 \\
Saline HFD & $42.6 \pm 4.8$ & $4.1 \pm 0.7^{\mathrm{ac}}$ & 0.09 \\
HCi HFD & $45.3 \pm 3.9^{\mathrm{c}}$ & $2.7 \pm 0.2^{\mathrm{b}}$ & 0.10 \\
HGHCi HFD & $27.3 \pm 3.5^{\mathrm{b}}$ & $3.2 \pm 0.7^{\mathrm{c}}$ & 0.08 \\
LDLR KO HFD & $39.2 \pm 3.4$ & & \\
& & & \\
Paigen diet & Body weight & Liver weight & Liver/body weight \\
& {$[\mathrm{g}]$} & & ratio \\
\hline 8 weeks & & $2.0 \pm 0.1$ & 0.06 \\
Saline PD & $31.1 \pm 1.2$ & $1.7 \pm 0.2$ & 0.05 \\
HCi Paigen & $32.0 \pm 3.5$ & $2.7 \pm 0.1^{\mathrm{b}}$ & 0.14 \\
HGHCi Paigen & $19.7 \pm 3.1^{\mathrm{b}}$ & $1.6 \pm 0.2$ & 0.06 \\
LDLR KO Paigen & $27.9 \pm 1.6^{\mathrm{b}}$ & &
\end{tabular}

Supplementary Table 1. Data are shown as mean \pm SEM and statistical comparisons between the groups were calculated using the one-way ANOVA and Sidak's posthoc test. ${ }^{a} p<0.05$ vs Saline HFD, ${ }^{b} p<0.05$ vs HCi HFD, ${ }^{c} p<0.05$ vs 12 weeks. HFD: highfat diet; HCi: hyperlipidemia model; HGHCi: hyperglycemia + hyperlipidemia model; PD: Paigen diet 
Supplementary Figure I. PD fed HGHCi mice showed higher mortality than HFD fed mice.

A

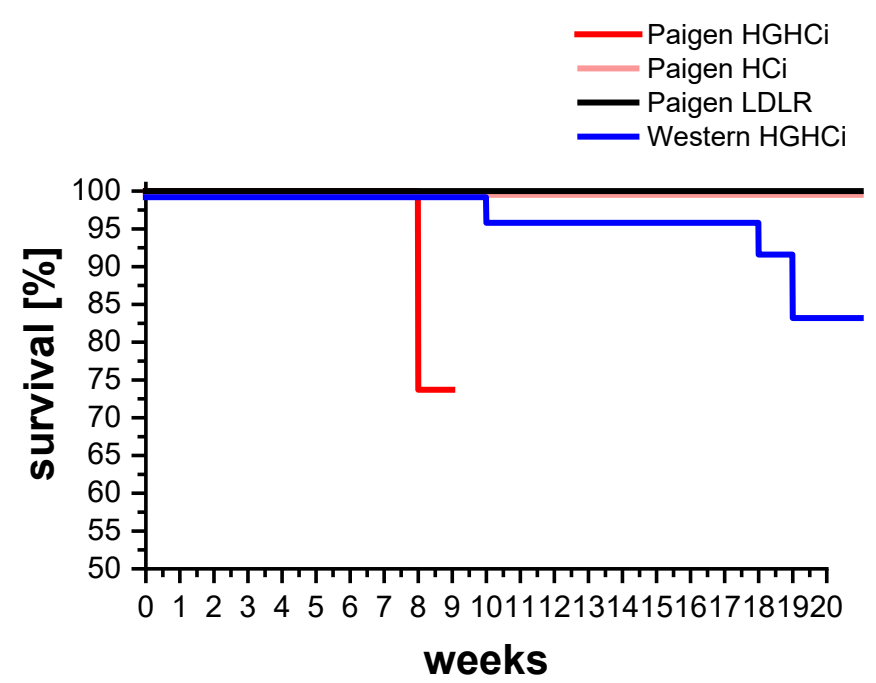

Supplementary Figure I. A: Kaplan-Meier survival curves of $\mathrm{HGHCi}, \mathrm{HCi}$ and LDL receptor $\mathrm{KO}$ mice on Paigen diet compared to HGHCi mice on Western diet (high-fat diet, HFD). 
Supplementary Figure II. Comparison with HFD fed LDLR KO mice.

A

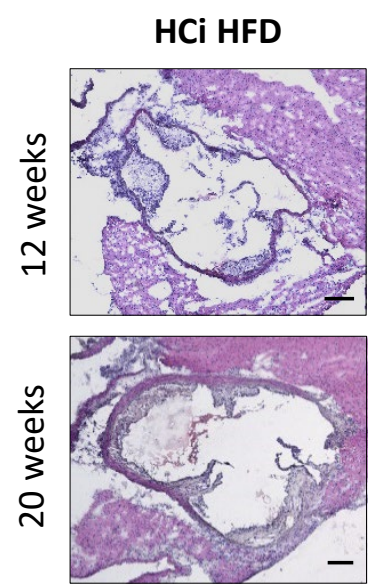

C
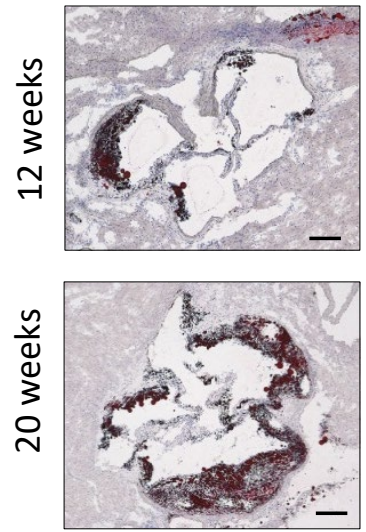

E
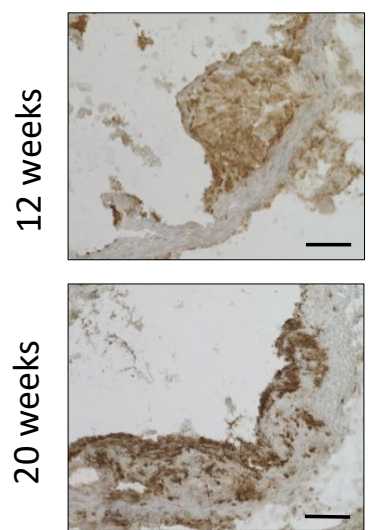

G
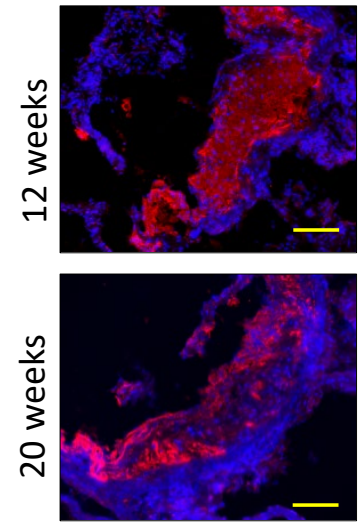

MOMA-2/ DAPI
B
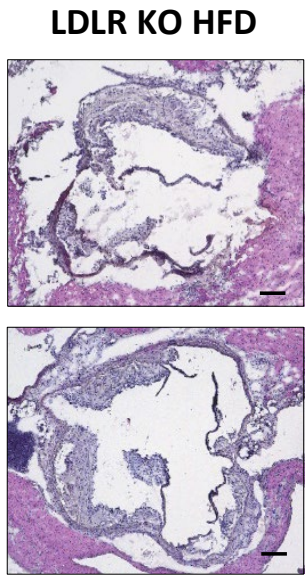

D
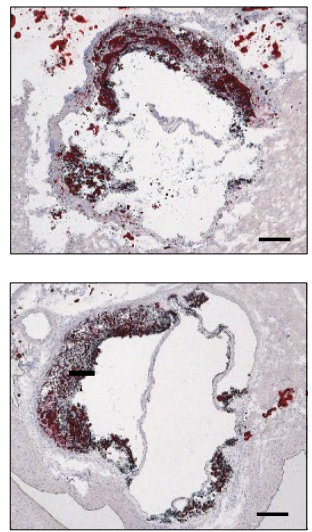

$\mathbf{F}$
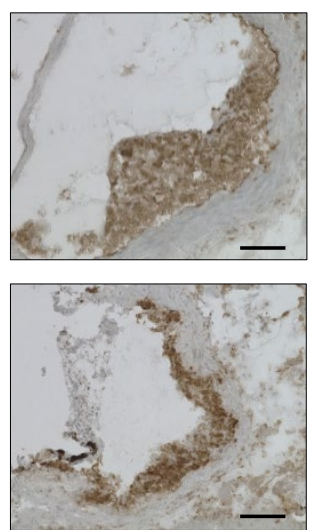

H
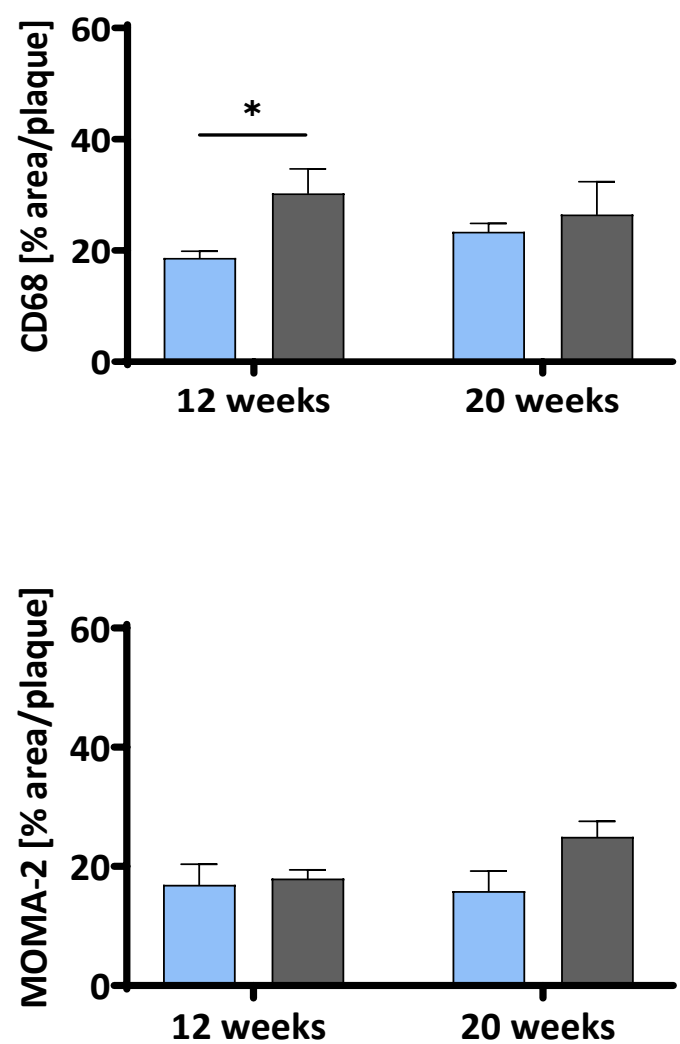
Supplementary Figure II. Comparison with HFD fed LDLR KO mice. A-H: Representative histological images showing aortic root sections stained with Hematoxylin Eosin (H \& E, A) and bar graphs summarizing data (B). Representative histological images showing aortic root sections stained with Oil-red-O (C) and bar graphs summarizing data (D) E: Representative images showing immunohistochemical staining of aortic root sections for macrophages marker CD68 (positive cells detected by HRP-DAB reaction, brown) and bar graphs summarizing data $(\mathbf{F})$. Representative images showing immunofluorescence staining of aortic root sections for macrophages marker MOMA-2 (G, MOMA-2, red; DAPI nuclear counterstain, blue) and bar graphs summarizing data. Stainings are imaged at $20 \times$ magnification, Scale bar $100 \mu \mathrm{m}$. 
Supplementary Figure III. Comparison with Paigen fed LDLR KO mice.

A

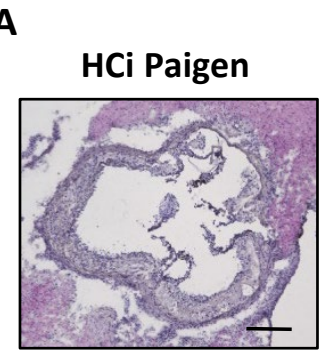

c

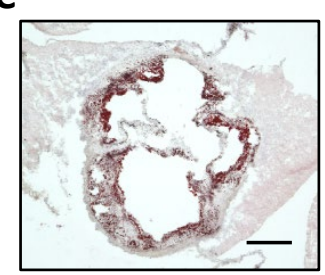

E
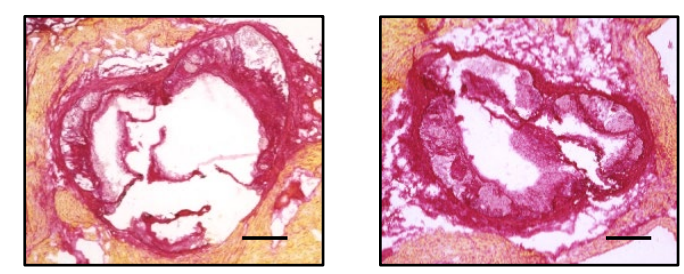

G
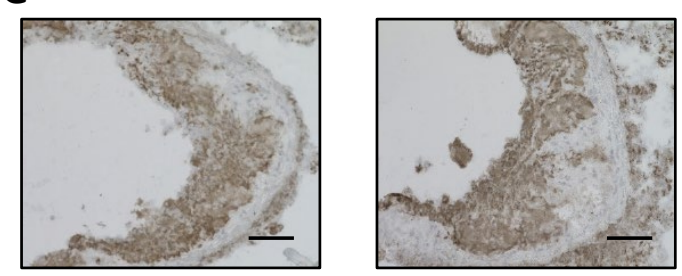

I
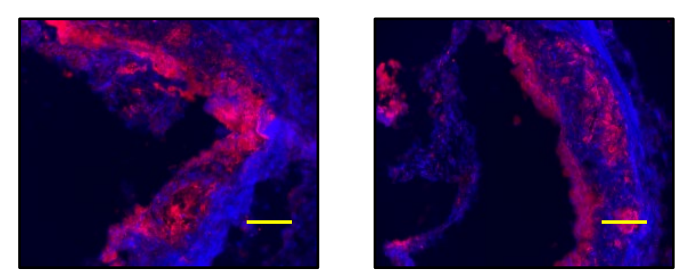

K
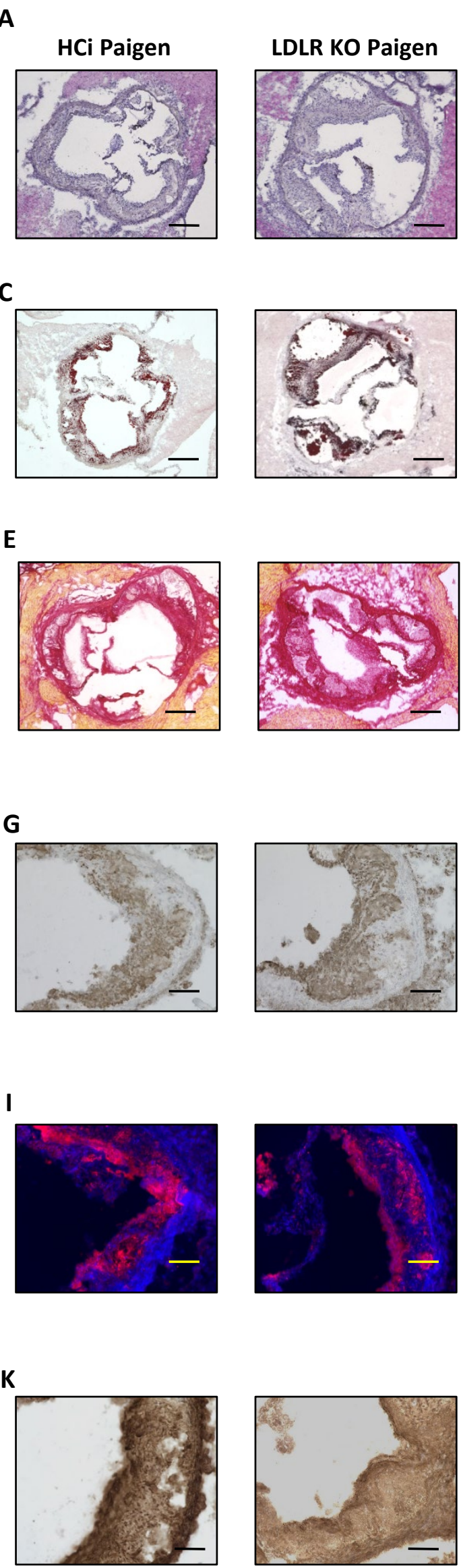

F

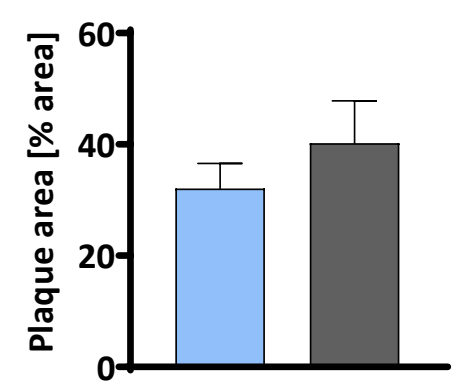

D
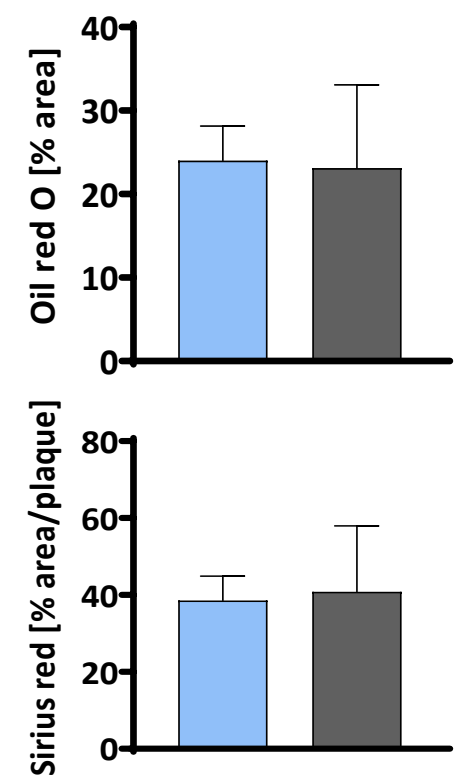

H

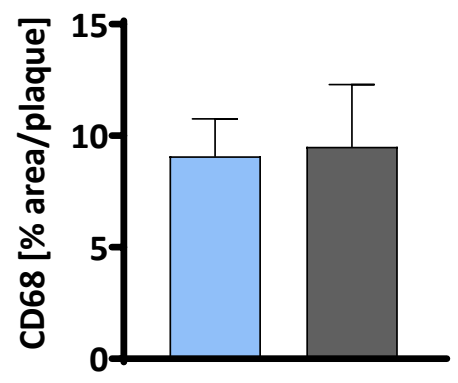

J

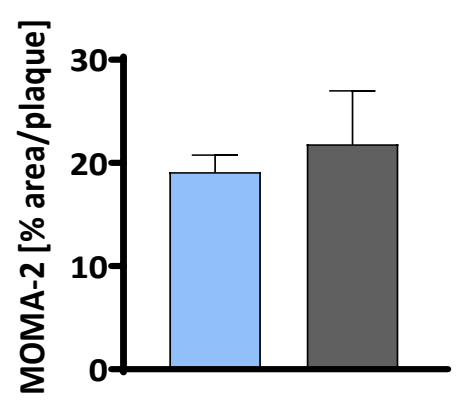

L
HCi Paigen

LDLR KO Paigen

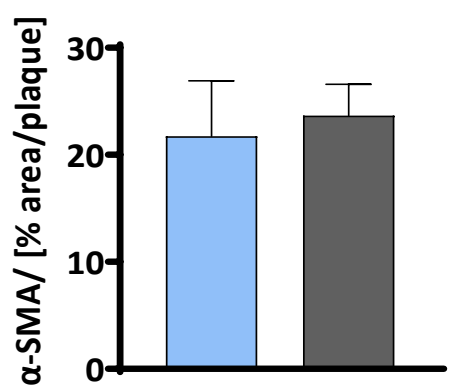


Supplementary Figure III. Comparison with Paigen diet fed LDLR KO mice. A-L: Representative histological images showing aortic root sections stained with Hematoxylin Eosin (H \& E, A) and bar graphs summarizing data (B). Representative histological images showing aortic root sections stained with Oil-red-O (C) and bar graphs summarizing data (D). Representative histological images showing aortic root sections stained with Sirius Picric Red (E) and bar graphs summarizing data (F) G: Representative images showing immunohistochemical staining of aortic root sections for macrophages marker CD68 (positive cells detected by HRP-DAB reaction, brown) and bar graphs summarizing data $(\mathbf{H})$. Representative images showing immunofluorescence staining of aortic root sections for macrophages marker MOMA-2 (I, MOMA-2, red; DAPI nuclear counterstain, blue) and bar graphs summarizing data. Stainings are imaged at $20 \times$ magnification, Scale bar $100 \mu \mathrm{m}$ (J). K: Representative images showing immunohistochemical staining of aortic root sections for macrophages marker alpha smooth muscle actin (positive cells detected by HRP-DAB reaction, brown) and bar graphs summarizing data $(\mathbf{L})$. 
Supplementary Figure IV. Hyperglycemia alone does not affect plasma cholesterol levels in mice fed a Paigen diet.

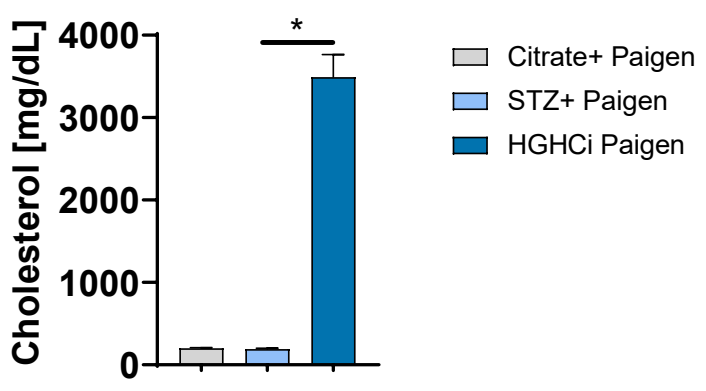

Supplementary Figure IV. Hyperglycemia alone does not affect plasma cholesterol levels in mice fed a Paigen diet. Comparison of cholersterol levels in HGHCi mice $(\mathrm{N}=13)$, streptozotocin (STZ) treated mice $(\mathrm{N}=5)$ and citrate controls $(\mathrm{N}=3)$ fed with Paigen diet. Plasma cholesterol leves $[\mathrm{mg} / \mathrm{dL}]$ were analyzed 12 weeks after induction of hypergylcemia with STZ. 


\section{Major Resources Table}

In order to allow validation and replication of experiments, all essential research materials listed in the Methods should be included

in the Major Resources Table below. Authors are encouraged to use public repositories for protocols, data, code, and other materials and provide persistent identifiers and/or links to repositories when available. Authors may add or delete rows as needed.

Animals (in vivo studies)

\begin{tabular}{|l|l|l|l|l|}
\hline \multicolumn{1}{|c|}{ Species } & \multicolumn{1}{|c|}{ Vendor or Source } & Background Strain & Sex & \multicolumn{1}{c|}{ Persistent ID / URL } \\
\hline Mouse & $\begin{array}{l}\text { Charles River } \\
\text { Laboratories }\end{array}$ & C57BL/6N & male & $\frac{\text { C57BL/6 Mouse } / \text { Charles }}{\text { River Laboratories. }}$ \\
\hline & & & & \\
\hline & & & & \\
\hline
\end{tabular}

\section{Genetically Modified Animals}

\begin{tabular}{|l|l|l|l|l|l|}
\hline & Species & $\begin{array}{c}\text { Vendor or } \\
\text { Source }\end{array}$ & $\begin{array}{c}\text { Background } \\
\text { Strain }\end{array}$ & $\begin{array}{c}\text { Other } \\
\text { Information }\end{array}$ & \multicolumn{1}{|c|}{ Persistent ID / URL } \\
\hline $\begin{array}{l}\text { Parent - } \\
\text { Male }\end{array}$ & Mouse & $\begin{array}{l}\text { The Jackson } \\
\text { Laboratory }\end{array}$ & $\begin{array}{l}\text { 000664 } \\
\text { C57BL/6J }\end{array}$ & $\begin{array}{l}\text { B6.129S7- } \\
\text { Ldlrtm1Her/J } \\
\text { Stock No: } \\
002207\end{array}$ & https://www.jax.org/strain/002207 \\
\hline $\begin{array}{l}\text { Parent - } \\
\text { Female }\end{array}$ & Mouse & $\begin{array}{l}\text { The Jackson } \\
\text { Laboratory }\end{array}$ & $\begin{array}{l}\text { 000664 } \\
\text { C57BL/6J }\end{array}$ & $\begin{array}{l}\text { B6.129S7- } \\
\text { Ldlrtm1Her/J } \\
\text { Stock No: } \\
002207\end{array}$ & https://www.jax.org/strain/002207 \\
& & & & & \\
\hline
\end{tabular}

\section{Antibodies}

\begin{tabular}{|c|c|c|c|c|c|}
\hline $\begin{array}{c}\text { Target } \\
\text { antigen }\end{array}$ & $\begin{array}{l}\text { Vendor } \\
\text { or Source }\end{array}$ & Catalog \# & $\begin{array}{c}\text { Working } \\
\text { concentration }\end{array}$ & $\begin{array}{l}\text { Lot \# } \\
\text { (preferred but } \\
\text { not required) }\end{array}$ & Persistent ID / URL \\
\hline $\mathrm{mLDLR}$ & $\begin{array}{l}\text { R\&D } \\
\text { System, } \\
\text { United } \\
\text { States }\end{array}$ & AF2255 & $1: 200$ & & $\begin{array}{l}\text { https://www.rndsystems.com/products/m } \\
\text { ouse-Idlr-antibody_af } 2255\end{array}$ \\
\hline $\mathrm{m} \beta$-actin & $\begin{array}{l}\text { Abcepta } \\
\text { Inc., } \\
\text { United } \\
\text { States }\end{array}$ & AM1829B & $1: 10,000$ & & $\begin{array}{l}\text { https://www.abcepta.com/products/AM18 } \\
\text { 29b-Beta-Actin-Antibody }\end{array}$ \\
\hline $\begin{array}{l}\text { Goat IgG } \\
\text { HRP }\end{array}$ & $\begin{array}{l}\text { Agilent } \\
\text { Technolo } \\
\text { gies, } \\
\text { United } \\
\text { States }\end{array}$ & P0449 & $1: 1,000$ & & $\begin{array}{l}\text { https://www.agilent.com/store/en_US/LCa } \\
\text { t-SubCat3ECS_244797/Rabbit-Anti-Goat- } \\
\text { Immunoglobulins-HRP }\end{array}$ \\
\hline $\begin{array}{l}\text { Mouse IgG } \\
\text { HRP }\end{array}$ & $\begin{array}{l}\text { Agilent } \\
\text { Technolo } \\
\text { gies, } \\
\text { United } \\
\text { States }\end{array}$ & P0447 & $1: 10,000$ & & $\begin{array}{l}\text { https://www.agilent.com/en/product/imm } \\
\text { unohistochemistry/antibodies- } \\
\text { controls/secondary-antibodies/goat-anti- } \\
\text { mouse-immunoglobulins-hrp-(affinity- } \\
\text { isolated)-153239 }\end{array}$ \\
\hline mMOMA-2 & $\begin{array}{l}\text { abcam, } \\
\text { Germany }\end{array}$ & ab33451 & $1: 100$ & & $\begin{array}{l}\text { https://www.abcam.com/monocyte-- } \\
\text { macrophage-antibody-moma-2- } \\
\text { ab33451.html }\end{array}$ \\
\hline
\end{tabular}

DOI [to be added] 


\begin{tabular}{|l|l|l|l|l|l|}
\hline mCD68 & $\begin{array}{l}\text { abcam, } \\
\text { Germany }\end{array}$ & ab125212 & $1: 1,000$ & & $\begin{array}{l}\text { https://www.abcam.com/cd68-antibody- } \\
\text { ab125212.html }\end{array}$ \\
\hline $\begin{array}{l}\text { Mouse } \\
\text { alpha } \\
\text { smooth } \\
\text { muscle } \\
\text { actin (ma- } \\
\text { SMA) }\end{array}$ & $\begin{array}{l}\text { abcam, } \\
\text { Germany }\end{array}$ & ab124964 & $1: 250$ & & $\begin{array}{l}\text { https://www.abcam.com/alpha-smooth- } \\
\text { muscle-actin-antibody-epr5368- } \\
\text { ab124964.html }\end{array}$ \\
\hline $\begin{array}{l}\text { Rat IgG } \\
\text { Alexa Fluor } \\
\text { 568 }\end{array}$ & $\begin{array}{l}\text { ThermoFi } \\
\text { sher, } \\
\text { United } \\
\text { States }\end{array}$ & A-11077 & $1: 100$ & & \\
\hline $\begin{array}{l}\text { anti-rabbit } \\
\text { HRP }\end{array}$ & $\begin{array}{l}\text { Vector } \\
\text { Laborator } \\
\text { ies, Inc., } \\
\text { Unites } \\
\text { States }\end{array}$ & MP-7801 & & & $\begin{array}{l}\text { https://www.thermofisher.com/antibody/p } \\
\text { roduct/Goat-anti-Rat-IgG-H-L-Cross- } \\
\text { Adsorbed-Secondary-Antibody-Polyclonal/ }\end{array}$ \\
\hline
\end{tabular}

\section{DNA/cDNA Clones}

\begin{tabular}{|c|c|c|c|}
\hline Clone Name & Sequence & Source / Repository & Persistent ID / URL \\
\hline & & & \\
\hline & & & \\
\hline & & & \\
\hline
\end{tabular}

\section{Cultured Cells}

\begin{tabular}{|l|l|l|l|}
\hline Name & Vendor or Source & Sex (F, M, or unknown) & Persistent ID / URL \\
\hline & & & \\
\hline & & & \\
\hline & & & \\
\hline
\end{tabular}

Data \& Code Availability

\begin{tabular}{|c|c|c|}
\hline Description & Source / Repository & Persistent ID / URL \\
\hline & & \\
\hline & & \\
\hline & & \\
\hline
\end{tabular}

\section{Other}

\begin{tabular}{|l|l|l|}
\hline \multicolumn{1}{|c|}{ Description } & \multicolumn{1}{c|}{ Source / Repository } & Persistent ID / URL \\
\hline BCA reagent & Perbio Science, Germany & \\
\hline Vectashield mounting medium with DAPI & Vector Laboratories, United States & \\
\hline Nitrocellulose membrane & Bio-Rad, USA & \\
\hline $\begin{array}{l}\text { Immobilon } \\
\text { HRP } \text { western chemiluminescent }\end{array}$ & Merck, Millipore, United States & \\
\hline Streptozotocin & Enzo Life Sciences, Germany & \\
\hline Oil-Red O & Sigma-Aldrich, Germany & \\
\hline Accu-chek test strips & Roche Diagnostics, Germany & \\
\hline Accu-check glucometer & Roche Diagnostics, Germany & \\
\hline Protease inhibitor cocktail & Roche Diagnostics, Germany & \\
\hline Albumin fraction V & Carl ROTH, Germany & \\
\hline Hematoxylin Gill II & Carl ROTH, Germany & \\
\hline
\end{tabular}

DOI [to be added] 


\begin{tabular}{|l|l|l|}
\hline Acrylamide & Carl ROTH, Germany & \\
\hline Agarose & Carl ROTH, Germany & \\
\hline Aqueous mounting medium & ZYTOMED, Germany & \\
\hline High fat diet & Ssniff, Germany & \\
\hline PBS & Life Technologies, Germany & \\
\hline Rompun & Bayer, Germany & \\
\hline Ketamine & Beta-pharm, Germany & \\
\hline & & \\
\hline
\end{tabular}

